Western University

Scholarship@Western

Department of Economics Research Reports

Economics Working Papers Archive

1983

\title{
Concurrent Renting and Selling in a Durable- Goods Monopoly Under Threat of Entry
}

Sam Bucovetsky

J Chilton

Follow this and additional works at: https://ir.lib.uwo.ca/economicsresrpt

Part of the Economics Commons

Citation of this paper:

Bucovetsky, Sam, J Chilton. "Concurrent Renting and Selling in a Durable-Goods Monopoly Under Threat of Entry." Department of Economics Research Reports, 8317. London, ON: Department of Economics, University of Western Ontario (1983). 
ISBN : $\quad 0-7714-0446-8$

RESEARCH REPORT 8317

CONCURRENT RENTING AND SELLING IN A DURABLE -GOODS MONOPOLY UNDER

THREAT OF ENTRY

by

S. Bucovetsky and J. Chilton

July 1983

Departmens of Economics Library

JUL 251983

Whiversity of Western Ontario 


\section{INTRODUCTION}

Coase (1972) and Bulow (1982) demonstrate the preference of a durable-goods monopolist for renting rather, than selling. ${ }^{1}$ The sales price consumers will pay today depends not pnly on the amount of the durable in circulation today, but also on future circulation. At any future date, however, the monopolist seller, takes as given past sales revenue, and for this reason has a tendency to overproduce. In the absence of the ability to commit its future' sales, it will always choose to rent rather than sell when given the opportunity. In contrast, competitive durable-goods equilibrium is the same with renting as with selling.

The preference of the monopolist for renting is not robust to relaxation of the no-entry assumption. The main result of this paper is that even a mild relaxation of the no-entry assumption may reverse the preference for renting over selling. Specifically, entry is assumed to take the form of the arrival of a single cournot rival at a known future date. When there is a temporary monopoly in this sense, selling prior to entry will in some cases be the preferred contract for transferring the rights to the use of the durable to consumefs. Indeed, even if after entry the established firm must behave à $1 a_{1}^{\prime}$ Cournot, the freedom to concurrently rent and sell prior to entry is sufficient to allow it to achieve the pattern of production and sales ${ }_{i}^{i}$ which maximizes its present value subject to the behavior of the entrant.

The explanation for this result should be of particular interest to readers familiar with recent work on commitment in the entry deterrence 1iterature. 2 Recent work has focussed on the role of capital in providing 
a first-mover advantage to established firms over the potential entrant. The general conclusion here is that because, it has the opportunity to lower its post-entry marginal cost function prior to entry, the established firm can move in the direction of the post-entry equilibrium it would choose if it could commit itself.

The established durable-goods firm which rents its product has this advantage: holding a stock of a durable gojod which can produce a corresponding level of services is equivalent to holding a stock of durable capacity which can be used to produce a corresponding level of nondurable goods. 3 Increasing pre-entry production of a durable--when it is rented--lowers post-entry marginal cost of providing services.

The ability to sell gives the established firm an additional advantage. If the established firm sells a unit of the durable good rather than renting it prior to entry, its post-entry incentives to sell are higher because perceived post-entry marginal revenue from an additional sale will be higher. That is, the very disadvantage of selling for the monopolist, brought to our attention by Coase (1972), may become an advantage for established firms threatened with entry. For example, suppose the established firm rents its pre-entry production. Suppose that, faced with the threat of entry, it is to its advantage to lower its post-entry marginal cost by increasing current production. Suppose further that (behaving as a Cournot duopolist after entry) it is unable to achieve its desired level of post-entry sales. By selling some of its production prior to entry it can raise its post-entry marginal revenue and move the post-entry equilibrium in the direction it desires while withholding enough to avoid overproducing. Sales and rentals have a certain duality. The first raises the established 
firm's post-entry marginal revenue; the second lowers its post-entry marginal cost.

The paper is organized as follows. Section II sets down the I

assumptions made with regard to consumer taistes and expectations, and with regard to costs. Section III presents the no-entry form of the model. Section IV states the post-entry Cournot duopoly equilibrium in terms of past production and past sales by the established firm. Sections V, VI, VII, and VIII consider various forms of the problem faced by the established firm. In isection $V$, the assumption that the established firm behaves à 1 a cournot after entry is effectively suspended by assuming it can precommit post-entry behavior. The precommitment plan is then compared to the plan when it cannot explicitly precommit, and can only rent (Section VI), only sell (Section VII), and can both rent and sell (Section VIII). It is shown that the Cournot renter cannot always achieve the precommitment optimum. And the preference the durable goods producer has for renting is weakened severely by the entry threat. In some cases the established firm will prefer selling to renting; in general the advantage of renting over selling is reduced. It is shown that the seller is more likely to deter entry than the renter. In general, just as in the no-entry case selling will result in greater consumption of services in every time period. Finally, the freedom to concurrently rent and sell is sufficient to effectively achieve the precommitment plan. ${ }^{4}$

In Section IX an alternative form of the post-entry equilibrium concept is considered where entry results in the competitive equilibrium. It is shown that the established firm is indifferent between renting and selling in the pre-entry period. Section $X$ summarizes. 
II. DEMAND, EXPECTATIONS, AND COSTS

The assumptions made here are essentially those of Bulow (1982).

Let $r_{t}$ denote the price of a unit of services of the durable good in time period $t$. The inverse demand for services is

$$
\mathbf{r}_{t}=\phi\left(q_{t}\right)
$$

where $q_{t}$ is the level of services demanded in period $t$ at a price $r_{t}$. It will be noted that service demand is assumed to be time independent and independent of the price of services in other periods. It is assumed $\phi(q) \geq 0, \phi^{\prime}(q)<0$, and $\phi^{\prime \prime}(q) \leq 0$. The linear form

$$
\not(q)=\alpha-\beta q
$$

will be used when closed-form solutions are desired. Bulow primarily considers the linear case.

Services equal the quantity of the durable good in use. The durable does not depreciate with time or uşe; its durability is exogenously given. (Moral hazard is assumed away.) Thẹre are two time periods, $t=1,2$. The discount factor is $\delta$, where $0, \leq \delta \leq 1$.

By definition, renting transfers the use of the durable to the consumer for one period. Hence, the rental price equals the services price. To sell, on the other hand, is defined as the transfer of all present and future use of the durable. As in Bulow (1982), the sales price in period $t, p_{t}$, satisfies

$$
\mathbf{p}_{1}=\varnothing\left(\mathrm{q}_{1}\right)+\delta \mathrm{p}_{2}
$$

and

$$
p_{2}=\varnothing\left(q_{2}\right)
$$

There are two assumptions implicit in equation (1). The first is the existence of a perfect secondhand market. Effectively there exist 
competitive intermediaries who buy the good from the manufacturer(s) and rent the product to consumers. The second lassumption is that buyers in the first period foresee the second period price as a known function of firstperiod production, and first-period sales.:

Constant marginal costs, $c$, are assumed. There are no other costs of production, nor are there any costs of delivering the services to the consumer. Bulow (1982) considers capacity ${ }_{i} \cos t s$ and other ways for the monopolist seller to ensure buyers of a second period service price.

These are not considered here. 


\section{NO ENTRY THREAT}

The results of this section are contained in Bulow (1982), but are repeated here for completeness. Let firm 1 be the established firm. Denote by $x_{t}^{i}$ the production of firm $i$ in period $t$. of course in this section the "i" index is redundant; the possibility of $x_{t}^{2}>0$ will be admitted only in subsequent sections.

The present value of the firm's profits is

$$
v\left(x_{1}^{1}, x_{2}^{1}\right)=\left(\phi\left(x_{1}^{1}\right)-c\right) x_{1}^{1}+\delta\left[\phi\left(x_{1}^{1}+x_{2}^{1}\right)\left(x_{1}^{1}+x_{2}^{1}\right)-c x_{2}^{1}\right]
$$

or equivalently

$$
\text { (3') } v\left(x_{1}^{1}, x_{2}^{1}\right)=\left[\phi\left(x_{1}^{1}\right)+\delta \phi\left(x_{1}^{1}+x_{2}^{1}\right)-c\right] x_{1}^{1}+\delta\left[\phi\left(x_{1}^{1}+x_{2}^{1}\right)-c\right] x_{2}^{1}
$$

where the alternative arrangement of terms indicate the equivalence of renting and selling for a given pattern of services over time. If the monopolist can precommit itself beforehand to any choice of $x_{1}^{1}$ and $x_{2}^{1}$, it will choose those variables to maximize $V$. It can be seen that the monopolist will never choose a positive level of second-period production. For if $x_{2}^{1}>0$, first-order conditions $\frac{\partial \mathrm{V}}{\partial \mathrm{x}_{2}^{1}}=0 \mathrm{imply}$

(4) $\phi\left(x_{1}^{1}+x_{2}^{1}\right)+\left(x_{1}^{1}+x_{2}^{1}\right) \phi^{\prime}\left(x_{1}^{1}+x_{2}^{1}\right)-c=0$

Since $\frac{\partial v}{\partial x_{1}^{1}}=\phi\left(x_{1}^{1}\right)+x_{1}^{1} \phi^{\prime}\left(x_{1}^{1}\right)-c+\delta\left[\phi\left(x_{1}^{1}+x_{2}^{1}\right)+\left(x_{1}^{1}+x_{2}^{1}\right) \phi^{\prime}\left(x_{1}^{1}+x_{2}^{1}\right) \cdot\right]$, equation (4) implies

$$
\frac{\partial v}{\partial x_{1}^{1}}=\phi\left(x_{1}^{1}\right)+x_{1}^{1} \phi^{\prime}\left(x_{1}^{1}\right)-(1-\delta) c
$$

But the concavity of $\phi$ and equation (4) then imply $\frac{\partial V}{\partial x_{1}^{1}}>0$ which is of course inconsistent with the optimality of $x_{1}^{1}$. Hence the monopolist's optimam 
involves $x_{2}^{1}=0$. The optimal first-period production then obeys

$$
\left\{\begin{array}{l}
x_{1}^{1}=0 \text { if }(1+\delta) \phi(0) \leq c \\
(1+\delta)\left[\phi\left(x_{1}^{1}\right)+x_{1}^{1} \phi^{\prime}\left(x_{1}^{1}\right)\right]-c=0 \text { otherwise }
\end{array}\right\}
$$

Table 1 solves equation (5) in the case of linear demand.

The monopolist can achieve this optimum by renting, even if it cannot explicitly precommit. In the second period, the renter will wish to choose $\mathrm{x}_{2}^{1}$ to maximize second-period income $\phi\left(\mathrm{x}_{1}^{1}+\mathrm{x}_{2}^{1}\right)\left(\mathrm{x}_{1}^{1}+\mathrm{x}_{2}^{1}\right)-c \mathrm{x}_{2}^{1}$. But equation (3) shows that this is exactly the problem of choosing $x_{2}^{1}$ to maximize $\mathrm{v}\left(\mathrm{x}_{1}^{1}, \mathrm{x}_{2}^{1}\right)$.

If the monopolist sells its output, however, it will try, in the second period, to maximize current sales revenue $\left[\phi\left(\mathrm{x}_{1}^{1}+\mathrm{x}_{2}^{1}\right)-\mathrm{c}\right] \mathrm{x}_{2}^{1}$. Equation (3') shows that this problem is not the same as maximizing $v\left(x_{1}^{1}, x_{2}^{1}\right)$ with respect to $x_{2}^{1}$ since the term $\phi\left(x_{1}^{1}+x_{2}^{1}\right) x_{1}^{1}$, representing the influence of secondperiod production on first-period sales revenue, is being ignored. If the seller cannot precommit, its second-period production will be the value of $\mathrm{x}_{2}^{1}$ which maximizes $\left[\phi\left(\mathrm{x}_{1}^{1}+\mathrm{x}_{2}^{1}\right)-c\right] \mathrm{x}_{2}^{1}$, which defines $\mathrm{x}_{2}^{1}$ as a function of $x_{1}^{1}$, say $x\left(x_{1}^{1}\right)$. The seller can achieve the precommitment optimum if and only if $x\left(x_{1}^{1}\right)=0$, when $x_{1}^{1}$ is the optimal production level defined in equation (5) above. Let $Q$ be the level of services where price equals marginal cost, $\phi(Q)=c$. Then $x$ can be defined by

$$
\begin{cases}\phi(X+x(x))+\chi(x) \phi^{\prime}(x+x(x))-c=0 & \text { if } x<Q \\ x(x)=0 & \text { if } x \geq Q\end{cases}
$$

For future reference, note 
(7) $x^{\prime}(x)= \begin{cases}-\frac{\phi^{\prime}(X+x(x))+x(x) \phi^{\prime \prime}(X+x(x))}{2 \phi^{\prime}(X+x(x))+x(x) \phi^{\prime \prime}(x+x(x))} & \text { if } x<Q \\ 0 & \text { if } x \geq Q\end{cases}$

so that

$$
0 \geq x^{\prime}(x) \geq-\frac{1}{2}
$$

Thus if the optimal $x_{1}^{1}$ in equation (5) exceeds $Q, x\left(x_{1}^{1}\right)=0$. Modifying Bain's terminology, self-entry is blockaded. Otherwise the seller must choose $x_{1}^{1}$ to maximize $\left(\phi\left(x_{1}^{1}\right)-c\right) x_{1}^{1}+\delta\left[\phi\left(x_{1}^{1}+x\left(x_{1}^{1}\right)\right)\left(x_{1}^{1}+x\left(x_{1}^{1}\right)\right)-c x\left(x_{1}^{1}\right)\right]$. If

$$
\begin{gathered}
(1+\delta)\left[\phi(Q)+Q \phi^{\prime}(Q)\right]+\delta\left[Q \phi^{\prime}(Q)-c\right] X^{\prime}(Q) \\
\geq c \geq \\
(1+\delta)\left[\phi(Q)+Q \phi^{\prime}(Q)\right]
\end{gathered}
$$

then the seller picks $x_{1}^{1}=Q$ so that $x_{2}^{1}=x\left(x_{1}^{1}\right)=0$. Such a large level of first-period production is chosen that self-entry is effectively impeded. If the first inequality in (8) does not hold, then self-entry is ineffectively impeded. First-order conditions for $x_{1}^{1}$ then imply

$$
\begin{aligned}
& \phi\left(\mathrm{x}_{1}^{1}\right)+\mathrm{x}_{1}^{1} \phi^{\prime}\left(\mathrm{x}_{1}^{1}\right)-c+\delta\left[\phi\left(\mathrm{x}_{1}^{1}+x\left(\mathrm{x}_{1}^{1}\right)\right)+\left(\mathrm{x}_{1}^{1}+x\left(\mathrm{x}_{1}^{1}\right)\right) \phi^{\prime}\left(\mathrm{x}_{1}^{1}+x\left(\mathrm{x}_{1}^{1}\right)\right)\right]+ \\
& +\delta\left[\phi\left(\mathrm{x}_{1}^{1}+x\left(\mathrm{x}_{1}^{1}\right)\right)+\left(\mathrm{x}_{1}^{1}+x\left(\mathrm{x}_{1}^{1}\right)\right) \phi^{\prime}\left(\mathrm{x}_{1}^{1}+x\left(\mathrm{x}_{1}^{1}\right)\right)-c\right] x^{\prime}\left(\mathrm{x}_{1}^{1}\right)=0
\end{aligned}
$$

By comparing (5) and (9), it can be shown that the seller provides at least as high a level of service of the durable good as the renter in each period. Table 2 shows the monopoly seller's optimum when demand is linear; note that the commitment problem arises as the demand parameter $\alpha$ becomes large relative to the marginal cost of production. 
IV. POST-ENTRY EQUILIBRIUM IS COURNOT

This section develops the post-entry equilibrium concept to be used in Sections V, VI, and VII in deriving the established firm's response to the threat of entry.

Entry is restricted to the appearance of a single additional firm in period 2. This entrant, firm 2, may produce in the second period, but not the first. Firm 1, the established firm, has a temporary monopoly; it alone is free to produce, rent, and sell in the first period as well as in the second period. Other than the constraints on firm 2 in the first period each firm has access to the technology described in Section II. In particular, there are no "entry fees" which must be incurred by firm 2 .

The behavioral assumption associated' with the second-period, or post-entry, game is Cournot. Each firmichooses its second-period sales (equivalently, rentals) to maximize its revenue net of costs taking as given the actions of its rival and any past sales by firm 1 . Iet

$$
\begin{aligned}
& x_{t}^{i} \equiv \text { production by firm } i \text { in period } t, \\
& y_{t}^{i} \equiv \text { rentals by firm } i \text { in period } t \\
& s_{t}^{i} \equiv \text { sales by firm } i \text { in period } t .
\end{aligned}
$$

By definition,

$$
\mathrm{Y}_{2}^{i}=\mathrm{s}_{2}^{i}, \quad i=1,2
$$

By assumption,

$$
\mathrm{x}_{1}^{2}=\mathrm{v}_{1}^{2}=\mathrm{s}_{1}^{2}=0
$$

Clearly, firm 2 will wish to sell ali it produces. Its profits can be written

$$
\text { (10) } \quad \pi^{2}\left(s_{2}^{2}, s_{1}^{1}+s_{2}^{1}\right) \equiv\left[\phi\left(s_{1}^{1}+s_{2}^{1}+s_{2}^{2}\right)-c\right] s_{2}^{2} \text {. }
$$


Let $s_{2}^{2}=\gamma^{2}\left(s_{1}^{1}+s_{2}^{1}\right)$ represent the cournot reaction function for the entrant. By definition,

$$
\pi^{2}\left(\gamma^{2}\left(s_{1}^{1}+s_{2}^{1}\right), s_{1}^{1}+s_{2}^{1}\right)=\max _{2}^{2} \pi^{2}\left(s_{2}^{2}, s_{1}^{1}+s_{2}^{1}\right)
$$

Note that $\gamma^{2}\left(s_{1}^{1}+s_{2}^{1}\right)=x\left(s_{1}^{1}+s_{2}^{1}\right)$, which was defined in Section III.

From the first-order condition and nonnegativity of $s_{2}^{2}, \gamma^{2}\left(s_{1}^{1}+s_{2}^{1}\right)$ satisfies

$$
\text { (11) }\left\{\begin{array}{l}
\phi\left(s_{1}^{1}+s_{2}^{1}+\gamma^{2}\left(s_{1}^{1}+s_{2}^{1}\right)\right)+\gamma^{2}\left(s_{1}^{1}+s_{2}^{1}\right) \phi^{0}\left(s_{1}^{1}+s_{2}^{1}+\gamma^{2}\left(s_{1}^{1}+s_{2}^{1}\right)\right)-c=0 \text { for } \phi\left(s_{1}^{1}+s_{2}^{1}\right)>c \\
\gamma^{2}\left(s_{1}^{1}+s_{2}^{1}\right)=0, \text { otherwise }
\end{array}\right\} \text {. }
$$

Second-period production by firm 1 , if any, will never be withheld. In period 2, firm 1 chooses $s_{2}^{1}$ to maximize

$$
\left.\begin{array}{l}
\pi^{1}\left(s_{2}^{1}, s_{1}^{1}+s_{2}^{2} ; x_{1}^{1}-s_{1}^{1}\right) \equiv \\
\phi\left(s_{1}^{1}+s_{2}^{1}+s_{2}^{2}\right) s_{2}^{1}, \text { for } s_{2}^{1} \leq x_{1}^{1}-s_{1}^{1} \\
\phi\left(s_{1}^{1}+s_{2}^{1}+s_{2}^{2}\right) s_{2}^{1}-c\left(s_{2}^{1}-\left(x_{1}^{1}-s_{1}^{1}\right)\right), \text { otherwise }
\end{array}\right\}
$$

In words, marginal cost is zero if desired second-period sales do not exceed unsold first-period production; otherwise marginal cost is c. Let $s_{2}^{1}=\gamma^{1}\left(s_{1}^{1}+s_{2}^{2} ; x_{1}^{1}-s_{1}^{1}\right)$ represent the cournot reaction function of firm 1 . By definition,

$$
\pi^{1}\left(\gamma^{1}\left(s_{1}^{1}+s_{2}^{2} ; x_{1}^{1}-s_{1}^{1}\right), s_{1}^{1}+s_{2}^{2} ; x_{1}^{1}-s_{1}^{1}\right)=\max _{s_{2}^{1}}^{1} \pi^{1}\left(s_{2}^{1}, s_{1}^{1}+s_{2}^{2} ; x_{1}^{1}-s_{1}^{1}\right)
$$

It is convenient to consider the artificial objective

(13) $\tilde{\pi}^{1}\left(s_{2}^{1}, s_{1}^{1}+s_{2}^{2} ; \xi\right) \equiv\left[\phi\left(s_{1}^{1}+s_{2}^{1}+s_{2}^{2}\right)-\xi\right] s_{2}^{1}$

Let the Cournot reaction $\tilde{\gamma}^{1}\left(s_{2}^{1}, s_{1}^{1}+s_{2}^{2} ; \xi\right)$ associated with (13) be defined by

$$
\tilde{\pi}^{1}\left(\tilde{\gamma}^{1}\left(s_{1}^{1}+s_{2}^{2} ; \xi\right)+s_{1}^{1}+s_{2}^{2} ; \xi\right)=\max _{2}^{1} \pi^{1}\left(s_{2}^{1}+s_{1}^{1}+s_{2}^{2} ; \xi\right)
$$


It should be transparent that when $c=\xi$ the artificial problem is symmetric to firm 2's problem. That is,

$$
\pi^{2}\left(\mu, s_{1}^{1}+\eta\right)=\tilde{\pi}^{1}\left(\mu, s_{1}^{1}+\eta ; c\right)
$$

and

$$
\gamma^{2}\left(\eta+s_{1}^{1}\right)=\tilde{\gamma}^{1}\left(\eta+s_{1}^{1} ; c\right)=\chi\left(\eta+s_{1}^{1}\right) \quad \forall(\mu, \eta) \in R_{+}^{2} \text {. }
$$

Moreover, $\gamma^{1}\left(s_{1}^{1}+s_{2}^{2} ; x_{1}^{1}-s_{1}^{1}\right)$ is easily described by

(14) $\gamma^{1}\left(s_{1}^{1}+s_{2}^{2} ; x_{1}^{1}-s_{1}^{1}\right)=$

$$
\left\{\begin{array}{l}
\tilde{\gamma}^{1}\left(s_{1}^{1}+s_{2}^{2} ; 0\right) \\
x_{1}^{1}-s_{1}^{1} \\
\tilde{\gamma}^{1}\left(s_{1}^{1}+s_{2}^{2} ; c\right)
\end{array}\right\} \text { as } s_{2}^{1}\left\{\begin{array}{r}
< \\
= \\
\vdots \\
>
\end{array}\right\} x_{1}^{1}-s_{1}^{1}
$$

where $\tilde{\gamma}^{1}\left(s_{1}^{1}+s_{2}^{2} ; \xi\right)$ must satisfy

$$
\left\{\begin{array}{l}
\phi\left(\tilde{\gamma}^{1}\left(s_{1}^{1}+s_{2}^{2} ; \xi\right)+s_{1}^{1}+s_{2}^{2}\right) \\
+\tilde{\gamma}^{1}\left(s_{1}^{1}+s_{2}^{2} ; \xi\right) \phi^{\prime}\left(\tilde{\gamma}^{1}\left(s_{1}^{1}+s_{2}^{2} ; \xi\right)+s_{1}^{1}+s_{2}^{2}\right)-\xi=0 \text { for } \phi\left(s_{1}^{1}+s_{2}^{2}\right)>\xi, \\
\tilde{\gamma}^{1}\left(s_{1}^{1}+s_{2}^{2} ; \xi\right)=0 \text {, otherwise. }
\end{array}\right\}
$$

The reaction $\gamma^{1}\left(s_{1}^{1}+s_{2}^{1} ; x_{1}^{1}-s_{1}^{1}\right)$ is illustrated in Figure 1 , along with the reference reactions $\tilde{\gamma}^{1}\left(s_{1}^{1}+s_{2}^{1} ; \xi\right)^{\prime}, \xi=0$,c.

In Figure 2 the axes of Figure 1 have been translated. After translation the loci express $s_{1}^{1}+s_{2}^{1}$ as a reaction to $s_{2}^{2}$. As $\gamma^{2}\left(s_{1}^{1}+s_{2}^{1}\right)$ expresses firm 2's reaction to $s_{1}^{1}+s_{2}^{1}$ it is convenient to express firm ${ }^{\prime}$ 's reaction in the same space. As should be evident from Figure 2, an increase 
In $s_{1}^{1}$ will shift out the reaction loci of Firm 1 . The kink in $\gamma^{1}\left(s_{1}^{1}+s_{2}^{2} ; x_{1}^{1}-s_{1}^{1}\right)+s_{1}^{1}$ at $s_{1}^{1}+s_{2}^{1}=x_{1}^{1}$ is comparable to Dixit (1980, Figure 2).

In Figure $3, \gamma^{2}\left(s_{1}^{1}+s_{2}^{2}\right), \tilde{\gamma}^{1}\left(s_{1}^{1}+s_{2}^{2} ; c\right)$ and $\tilde{\gamma}^{2}\left(s_{1}^{1}+s_{2}^{2} ; 0\right)$ are illustrated for given $s_{1}^{1}$. Define the symmetric post-entry Cournot-Nash equilibrium $\left(T\left(s_{1}^{1}\right)=\left(T^{1}\left(s_{1}^{1}\right), T^{2}\left(s_{1}^{1}\right)\right)\right.$ ) by the intersection of $\gamma^{2}\left(s_{1}^{1}+s_{2}^{1}\right)$ and $\tilde{\gamma}^{1}\left(s_{1}^{1}+s_{2}^{2} ; c\right)$. That is,

$$
\left\{\begin{array}{l}
T^{1}\left(s_{1}^{1}\right)=\tilde{\gamma}^{1}\left(s_{1}^{1}+T^{2} ; c\right)+s_{1}^{1} \\
\text { and } \\
T^{2}\left(s_{1}^{1}\right)=\gamma^{2}\left(s_{1}^{1}+T^{1}\right) .
\end{array}\right.
$$

Define the intersection of $\gamma^{2}\left(s_{1}^{1}+s_{2}^{1}\right)$ and ${ }^{\prime} \tilde{\gamma}^{1}\left(s_{1}^{1}+s_{2}^{2} ; 0\right)$ by $v\left(s_{1}^{1}\right)=\left(v^{1}\left(s_{1}^{1}\right), v^{2}\left(s_{1}^{1}\right)\right)$ where

$$
\left\{\begin{array}{l}
v^{1}=\tilde{\gamma}^{1}\left(s_{1}^{1}+v^{2} ; 0\right)+s_{1}^{1} \\
\text { and } \\
v^{2}=\gamma^{2}\left(s_{1}^{1}+v^{1}\right) .
\end{array}\right.
$$

As in Dixit (1980), the examination of the sensitivity of the postentry equilibrium to changes in $x_{1}^{1}$ can be reduced to the observation that given $s_{1}^{1}$, post-entry equilibrium lies on the segment of $\gamma^{2}\left(s_{1}^{1}+s_{1}^{2}\right.$;c) between $T$ and $V$. If $x_{1}^{1}<T^{1}$, the equilibrium is $T ;$ at the cournot equilibrium, $x_{2}^{1}>0$. If $x_{1}^{1}>v^{1}$, the equilibrium is $v$; Firm 1 withholds part of past production net of past sales from the market. Since $\gamma^{2}\left(s_{1}^{1}+s_{2}^{1}>0\right.$ if and only if $s_{1}^{1}+s_{2}^{1}<Q$, entry deterrence will be feasible for some given $s_{1}^{1}$ only if $\mathrm{V}\left(\mathrm{s}_{1}^{1}\right)>$ Q. If $\mathrm{T}^{1} \leq \mathrm{x}_{1}^{1} \leq \mathrm{v}^{1}$, then $\mathrm{s}_{1}^{1}+\mathrm{s}_{2}^{1}=\mathrm{x}_{1}^{1}$ and $\mathrm{s}_{2}^{2}=\gamma^{2}\left(\mathrm{x}_{1}^{1}\right)$. Given $x_{1}^{1}$ and $s_{1}^{1}$, Cournot equilibrium in the second period implicitly defines the 
value of Firm 1 in the second period $W\left(x_{1}^{1}, s_{1}\right)$ to be

$$
\left.\begin{array}{l}
W\left(x_{1}^{1}, s_{1}^{1}\right)= \\
\left\{\begin{array}{cc}
\phi\left(T^{1}\left(s_{1}^{1}\right)+T^{2}\left(s_{1}^{1}\right)\right)\left(T^{1}\left(s_{1}^{1}\right)-s_{1}^{1}\right) & c\left(T^{1}\left(s_{1}^{1}\right)-x_{1}^{1}\right. \\
\phi\left(x_{1}^{1}+\gamma^{2}\left(x_{1}^{1}\right)\right) x_{1}^{1} & \vdots \\
\phi\left(v^{1}\left(s_{1}^{1}\right)+v^{2}\left(s_{1}^{1}\right)\right) v^{1}\left(s_{1}^{1}\right) & \vdots \\
x_{1}^{1}<T^{1}\left(s_{1}^{1}\right) \\
T^{1}\left(s_{1}^{1}\right) \leq x_{1}^{1} v^{1}\left(s_{1}^{1}\right)
\end{array}\right\} \\
x_{1}>v^{1}\left(s_{1}^{1}\right)
\end{array}\right\}
$$

For the purpose of understanding the'dependence of segment TV on firstperiod sales of Firm $1, s_{1}^{1}$, it is easiest to consider the linear demand case. In this case,

$$
\begin{aligned}
& \gamma^{2}\left(s_{1}^{1}+s_{2}^{1}\right)=\frac{\alpha-\beta\left(s_{1}^{1}+s_{2}^{1}\right)-c}{2 \beta} \\
& \tilde{\gamma}^{1}\left(s_{1}^{1}+s_{2}^{2} ; 0\right)=\frac{\alpha-\beta\left(s_{1}^{1}+s_{2}^{2}\right)}{2 \beta}
\end{aligned}
$$

and

$$
\tilde{\gamma}^{1}\left(s_{1}^{1}+s_{2}^{2} ; c\right)=\frac{\alpha-\beta\left(s_{1}^{1}+s_{2}^{2}\right)-c}{2 \beta}
$$

These are illustrated in Figure 4 for two values of $s_{1}^{1}, \bar{s}_{1}^{1}<\bar{s}_{1}^{1}$. For simplicity, $\bar{s}_{1}^{1}=0$.

Figure 4 adds an additional element to the analyses of Dixit (1980) and Spulber (1981). For given first-period sales, Firm 1 can alter the post-entry Cournot equilibrium within the bounds TV by altering first-period production in a fashion similar to the effect of altering capacity in Dixit (1980 and Spulber (1981). 
In their models, advance sales by the established firm (i.e., contracts made prior to the entry threat for sales after entry) would work in the say $s_{1}^{1}$ does in our model, altering the segment $T V$. But in our model advance sales enter as a natural advantage for the established firm since the ability to sell a durable in period 1 effectively creates the opportunity to engage in advance sales for period 2. 


\section{ESTABLISHED FIRM CAN PRECOMMIT}

It is assumed throughout the remainder of this paper that firm 1 knows the reaction function of firm $2, \gamma^{2}(\cdot)$. Subject to the limitations placed on him by its own behavior in the second period, it maximizes its present value given $\gamma^{2}(\cdot)$. In this section it is assumed that the established firm may precommit itself to any level of second period sales it wishes. Equivalently, in this section the established firm rents in the first period, and in the second period plays Stackelberg choosing its post-entry sales to maximize second period profit given first period sales. That is, the Stackelberg renter, the firm which can rent in period 1 and play Stackelberg in the post-entry equilibrium can achieve the precommitment optimum under threat of entry. The Stackelberg problem is not studied here because of its plausibility. There is no compelling reason for a behavior asymmetry between the established firm and the entrant. However, the Stackelberg problem is a very helpful reference for studying the effect of the natural asymmetries of producing and selling by the established firm on the post-entry Cournot equilibrium.

Thus without loss of generality, it can be assumed that when precommitment is possible, firm 1 rents in period 1 and sells in period 2. Figure 5 illustrates the Cournot reaction functions for the case, $s_{1}^{1}=0$. Note, since renting and selling are equivalent in the second period, sales rather than rentals can be measured on the' axes without confusion. Let $M^{1}=\tilde{\gamma}^{1}(0 ; c)$ and $M^{2}=\gamma^{2}(0)$. By symmetry, ${ }^{1}=M^{2}=M$ where $M$ is the one period monopoly output,

$$
\phi(M)+M \phi^{\prime}(M)=c .
$$


Due to the constant average costs, either firm will want to produce at positive levels in the second period as long as price exceeds marginal cost. That is, $\tilde{\gamma}^{\top}(Q, c)=0=\gamma^{2}(Q)$, where $\phi(Q)=c$. Let $z^{1}$ satisfy $\hat{\gamma}^{1}\left(z^{1}, 0\right)=0$, so that $z^{1}$ is the level of first period sales inducing the established firm not to produce anymore, if production were costless. $\mathrm{Z}_{1}$ satisfies

$$
\phi\left(z^{1}\right)+z^{1} \phi^{\prime}\left(z^{1}\right)=0
$$

Clearly, $M<Q$. However,

$$
\mathrm{z}^{1}\left\{\begin{array}{l}
> \\
= \\
<
\end{array}\right) Q \text { as } c+\phi^{-1}(\mathrm{c}) \phi^{\prime}\left(\phi^{-1}(\mathrm{c})\right)\left(\begin{array}{l}
1 \\
> \\
1 \\
i
\end{array}\right) 0 .
$$

One case is trivial. If $(1+\delta) \phi(0) \leq c$, then in equilibrium there is no production by either firm.

With no entry threat the monopoly renter was seen in Section III to achieve the precommitment optimum $\left(x_{1}^{1}, x_{2}^{1}\right)$ given by (5). Thus, under the threat of entry, both the established Cournot renter and the established firm which can precommit will block entry if and only if $x_{1}^{1} \geq Q$. (This is a special case of Proposition 1 of Spulber (1981).) The condition whereby the monopoly seller's production plan is identicial to the production plan of the monopoly renter (blockaded self-entry) is also the condition whereby the no-entry precommitment (equivalently, the no-entry rental) plan blockades entry.

Suppose entry is not blockaded by the no-entry plan of the renter. The objective of the established renter in the second period is to maximize

$$
\pi^{1}\left(s_{2}^{1}, \gamma^{2}\left(s_{2}^{1}\right) ; x_{1}^{1}\right)
$$


where $\pi^{1}(\cdot, \cdot ; \cdot)$ is defined in (12). Let $s_{2}^{1}=\sigma^{1}\left(x_{1}^{1}\right)$ be the Stackelberg post-entry sales for firm 1 for given first-period production $x_{j}^{1}$. By definition,

$$
\pi^{1}\left(\sigma^{1}\left(x_{1}^{1}\right), \gamma^{2}\left(\sigma^{1}\left(x_{1}^{1}\right) ; x_{1}^{1}\right)=\max _{s_{2}^{1}} \pi^{1}\left(s_{2}^{1}, \gamma^{2}\left(s_{2}^{1}\right) ; x_{1}^{1}\right)\right.
$$

The Stackelberg sales $\sigma^{\top}\left(x_{7}^{T}\right)$ can be more fully characterized by considering the reference objective

$$
\tilde{\pi}^{1}\left(s_{2}^{1}, \gamma^{2}\left(s_{2}^{1}\right) ; s\right) \text {, }
$$

where $\tilde{\pi}^{1}(\cdot, \cdot ; \cdot)$ is defined in (13). Let $s_{2_{i}^{1}}^{1^{\prime}}=\tilde{\sigma}^{1}(\zeta)$ be the Stackelberg postentry sales for firm 1 for given cost of $s_{2}^{\lambda_{1}}, \xi_{1}$. By definition,

$$
\left.\tilde{\pi}^{1}\left(\tilde{\sigma}^{1}(\xi), \gamma^{2}\left(\tilde{\sigma}^{1}(\xi)\right) ; \xi\right)=\max _{s_{2}^{1}} \tilde{\pi}^{1} s_{2}^{1}, \gamma^{2}\left(s_{2}^{1}\right) ; \xi\right) \text {. }
$$

The first-order condition implicitly determines $s_{2}^{1}=\tilde{\sigma}^{1}(\xi)$ :

$$
\left\{\begin{array}{l:}
\phi\left(s_{2}^{1}+\gamma^{2}\left(s_{2}^{1}\right)\right)+s_{2}^{1} \phi^{\prime}\left(s_{2}^{1}+\gamma^{2}\left(s_{2}^{1}\right)\right)\left(1+\gamma^{2^{\prime}}\left(s_{2}^{1}\right)\right)-\xi=0, \\
\text { for } \phi(Q)+Q \phi^{\prime}(Q)\left(1+\gamma^{2^{\prime}}(Q)\right)-\xi<0 . \\
\text { and } s_{2}^{1}=Q \text {, otherwise }
\end{array}\right\}
$$

The Stackelberg sales $\sigma^{1}\left(x_{1}^{1}\right)$ can thus be defined in terms of the reference Stackelberg sales:

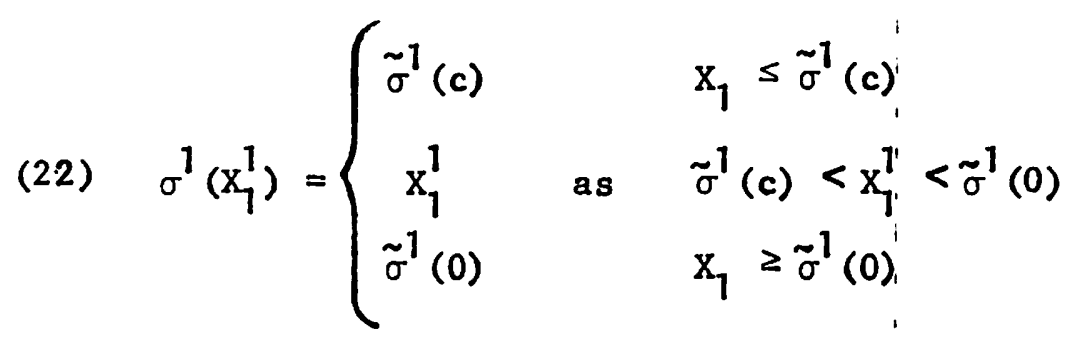


It follows that

$$
\begin{array}{ll}
\sigma^{1}(\zeta) \leq 0, & \\
\sigma^{1}\left(x_{1}^{1}\right)>T^{1}(0) & \forall x_{1}^{1}, \\
\sigma^{1}\left(x_{1}^{1}\right) \geq v^{1}(0) & V x_{1}^{1}>v^{1}(0)
\end{array}
$$

The objective of the Stackelberg renter is to choose $x_{1}^{1}$ to maximize

$$
\left[\phi\left(x_{1}^{1}\right)-c\right] x_{1}^{1}+\delta \pi^{1}\left(\sigma^{1}\left(x_{1}^{1}\right), \gamma^{2}\left(\sigma^{1}\left(x_{1}^{1}\right) ; x_{1}^{1}\right)\right)
$$

Let $\mathrm{x}_{1}^{1 *}$ be defined as the optimal first-period sales.

$$
\begin{aligned}
{\left[\phi\left(x_{1}^{1 *}\right)-c\right] x_{1}^{1 *}+\delta \pi^{1}\left(\sigma^{1}\left(x_{1}^{1 *}\right), \gamma^{2}\left(\sigma^{1}\left(x_{1}^{1 *}\right)\right) ; x_{1}^{1 *}\right) } \\
=\max _{x_{1}^{1}}\left\{\left[\phi\left(x_{1}^{1}\right)-c\right] x_{1}^{1}+\delta \pi^{1}\left(\sigma^{1}\left(x_{1}^{1}\right), \gamma^{2}\left(\sigma^{1}\left(x_{1}^{1}\right)\right) ; x_{1}^{1}\right)\right\} .
\end{aligned}
$$

Recall that with no entry threat, the renter with a permanent monopoly rented the same amount each period. Since' the rental marginal revenue function was the same in each period, if marginal revenue in period 2 exceeded marginal cost, it must also do so'in period 1 . It always paid to shift all production to the first period. 'Likewise, suppose it paid to withhold output in the second period. This implies rental marginal revenue in the second, and hence the first was negative. Withholding output in the second period never occurs in the absence of an entry threat. These results need not hold in the presence of an entry threat.

Under the threat of entry the inverse service demand faced by the established Stackelberg renter in the second period is

$$
\phi\left(s_{2}^{1}+\gamma^{2}\left(s_{2}^{1}\right)\right)
$$


Thus marginal revenue for the Stackelberg renter is

$$
\phi\left(s_{2}^{1}+\gamma^{2}\left(s_{2}^{1}\right)\right)+s_{2}^{1} \phi^{\prime}\left(s_{2}^{1}+\gamma^{2}\left(s_{2}^{1}\right)\right)\left(1+\gamma^{2}\left(s_{2}^{1}\right)\right) \text {. }
$$

From analysis of the static Stackelberg problem there is very little we can say about (28) as compared to monopoly marginal revenue,

$$
\phi\left(s_{2}^{1}\right)+s_{2}^{1} \phi^{\prime}\left(s_{2}^{1}\right) \text {. }
$$

The residual demand faced by firm 1 is below market demand; on the other hand since 5

$$
0>\gamma^{2^{\prime}}(\cdot) \geq-\frac{1}{2}
$$

the residual demand could still be more elastic.

Consider the conditions under which/entry is deterred. Clearly, if

$$
\phi(Q)+Q \phi^{\prime}(Q)\left(1+\gamma^{2^{\prime}}(Q)\right)-c z^{\prime} 0
$$

then entry will be deterred; this simply says it is profitable to deter entry even when some production is done in the second period. But since $\phi(Q)=c$ and $0 \geq \gamma^{2^{\prime}}(\cdot) \geq-\frac{1}{2}$, this simplifies to

$$
Q \phi^{\prime}(Q) \geq 0
$$

which is impossible except when $Q=0 .^{6}$ Thus, if entry is deterred, then $x_{2}^{7^{*}}=0$. That is, if entry is deterred, then

$$
(1+\delta)\left[\phi(Q)+Q \phi^{\prime}(Q)\right]+\delta Q \phi^{\prime}(Q) \gamma_{i}^{2^{\prime}}(Q)-c \geq 0
$$

and

$$
\phi(Q)+Q \phi^{\prime}(Q)+\delta c-c \geq 0
$$

Condition (31) ensures that producing only' in the first period is preferable to delaying some production to the second period. Indeed, (30) and (31) are necessary and sufficient for entry deterrence. Equation (31) simplifies to

$$
(2+\delta) Q \phi^{\prime}(Q)+2 \delta c \geq 0
$$


Solutions $x_{7}^{1 *}$ to (28) may be classified as follows.

Case A. $x_{1}^{1 *}>\sigma^{1}\left(x_{1}^{1 *}\right)$. The Stackelberg renter withholds output in the second period. As output $x_{1}^{1}$ is slack in the second period, $x_{1}^{1}$ is chosen with regard to its benefits in the first period; thus, $x_{1}^{1 *}=M^{1}$ by definition of $M^{1}$ as the single one-period monopoly output. Also: $\sigma^{1}\left(M^{1}\right)=\tilde{\sigma}^{1}(0)$ in this case. Moreover, since in this case $\sigma^{1}\left(M^{1}\right)<M^{1}$ entry is allowed because $M^{\top}<Q$, the entry preventing level of second-period sales. The necessary and sufficient condition for Case $A$ to apply is

$$
\phi\left(M^{1}+\gamma^{2}\left(M^{1}\right)\right)+M^{1} \phi^{\prime}\left(M^{1}+\gamma^{2}\left(M^{1}\right)\left(1+\gamma^{2}\left(M^{1}\right)\right)<0\right.
$$

Case B. $\mathrm{X}_{1}^{1 *}<\sigma^{1}\left(\mathrm{x}_{1}^{1 *}\right)$. The Stackelberg renter has positive production in the second period. Clearly, $s_{2}^{1 *}=\tilde{\sigma}^{1}(c)$. In this case $\mathrm{X}^{1 *}=\mathrm{E}^{1}$ where $\mathrm{E}^{1}$ satisfies

$$
\phi\left(E^{1}\right)+E^{1} \phi^{\prime}\left(E^{1}\right)-c+\delta c=0 .
$$

Clearly, $E^{1} \geq M^{1}$, by definition of $M^{1}$. In words, in the first period firm 1 produces up to the point where the extra revenue for each unit rented now is just offset by the cost savings due to delaying production one period. Second-period production satisfies

$$
\begin{aligned}
& \phi\left(E^{1}+x_{2}^{1}+\gamma^{2}\left(E^{1}+x_{2}^{1}\right)\right) \\
& +\left(E^{1}+x_{2}^{1}\right) \phi^{\prime}\left(E^{1}+x_{2}^{1}+\gamma^{2}\left(E^{1}+x_{2}^{1}\right)\right)\left(1+\gamma^{2^{\prime}}\left(E^{1}+x_{2}^{1}\right)\right)-c=0 .
\end{aligned}
$$

The necessary and sufficient condition for $\mathrm{x}_{7}^{1 *}=\mathrm{E}^{1}$ and (34) to describe the Stackelberg renter's plan is

$$
\phi\left(E^{1}+\gamma^{2}\left(E^{1}\right)\right)+\phi^{\prime}\left(E^{1}+\gamma^{2}\left(E^{1}\right)\right)\left(1+\gamma^{2^{\prime}}\left(E^{1}\right)\right)-c>0 .
$$


Case $c_{e} x_{1}^{1 *}=\sigma^{1}\left(x_{1}^{1 *}\right)$. The Stackelberg renter neither produces in the second period $\left(x_{1}^{2 *}=0\right)$, nor withholds first-period production from sale in the second period. First-period production $x_{1}^{1 *}$ is the value of $x_{1}^{1}$ satisfying

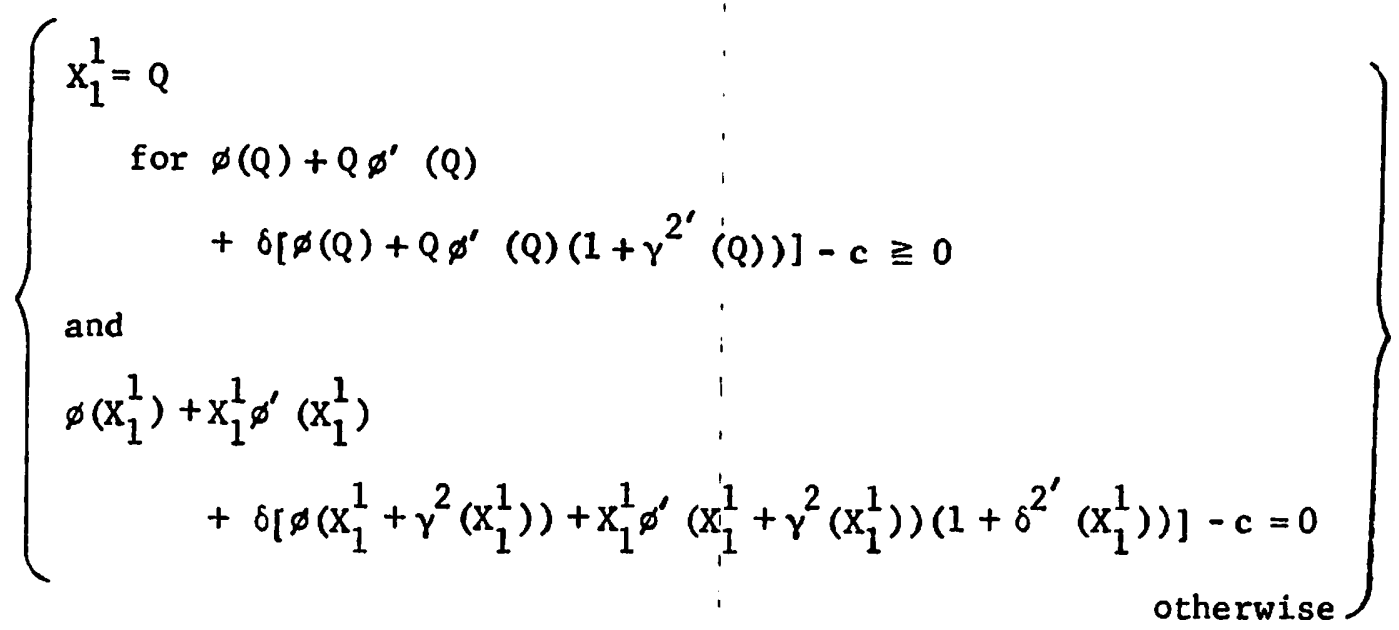

Case C applies if and only if,

$$
\phi\left(M^{1}+\gamma^{2}\left(M^{1}\right)\right)+M^{1} \phi^{\prime}\left(M^{1}+\gamma^{2}\left(M^{1}\right)\right)\left(1+\gamma^{2}\left(M^{1}\right)\right) \geqq 0
$$

and

$$
\phi\left(E^{1}+\gamma^{2}\left(E^{1}\right)\right)+E^{1} \phi^{\prime}\left(E^{1}+\gamma^{2}\left(E^{1}\right)\right)\left(1+\gamma^{\prime}\left(E^{1}\right)\right)-c<0 .
$$

(Note (31) implies $\phi\left(\mathrm{x}_{1}^{1 *}\right)+\mathrm{x}_{1}^{1 *} \phi^{\prime}\left(\mathrm{x}_{1}^{1 *}\right)+\delta_{1}-c>0$ )

Table 3 presents the Stackelberg renter--equivalent1y, precommitment-equilibrium under threat of entry with linear demand. Note, with linear demand $M^{1}=\tilde{\sigma}^{1}(c)$, Case A never arises. Likewise, Case $B$ never arises; it is sufficient to observe that if it pays to produce in the second period then $\tilde{\sigma}^{1}(c)>M^{1}$, a contradiction with linear demand. 
VI. ESTABLISHED COURNOT FIRM: THE CASE OF RENTING ONLY

In this section, it is assumed that firms are limited to offering contracts which only transfer the right to use the service provided by the durable good within the period the offer is made. This limitation is of no consequence to the established firm when it is Stackelberg in the post-entry equilibrium. However, in this section the established firm is assumed to play Cournot after entry. It will be shown that, contrary to the no-entry case, renting and precommitment are equivalent in some rather than in all cases.

This rent-only Cournot model is a special case of Spulber (1981, especially sections $I$ and II). When a durable good is rented, production of the good is equivalent to the installation of capacity to produce a nondurable good, services. Naturally, Spulber (1981) has variable costs of production in addition to capacity costs, making the rent-only cournot model considered here a special case of his.

Since for the renter $s_{1}^{1}=0$ by definition, the results of Section IV, and Figures 3-5 can be used to derive the post-entry Cournot equilibrium. This equilibrium depends on whether first-period production $x_{1}^{1}$ is large enough to put the established firm on its reaction curve appropriate for zero marginal cost. In particular

$$
\begin{cases}\text { if } x_{1}^{1} \leq T^{1}(0) & \text { then } x_{2}^{1}=T^{1}(0) \text { and } s_{2}^{1}=T^{1}(0) \\ \text { if } T^{1}(0)<x_{1}^{1}<v^{1}(0) & \text { then } x_{2}^{1}=0 \text { and } s_{2}^{1}=x_{1}^{1} \\ \text { if } x_{1}^{1} \geq v^{1}(0) & \text { then } x_{2}^{1}=0 \text { and } s_{2}^{1}=v^{1}(0)\end{cases}
$$

But the established firm:will always choose a level of first-period production $\mathrm{X}_{7}^{1}$ at least as large as the one-period monopoly output $M^{1}$. Since $M^{1}>T^{1}(0)$, 
the first line of (39) can never arise. The Cournot renter will never produce in the second period. Thus it will be unable to achieve the profits of the Stackelberg renter whenever the latter finds it optimal to produce after entry. In Section $V$ this situation was denoted Case $B$, and it was remarked that such a case could not arise when demand was linear. But there is another situation in which the Cournot renter cannot achieve the precommitment optimum. Equation (39) implies $s_{2}^{1} \leq v^{1}(0)$. Thus if the precommitment optimum involved a higher level of second-period sales than $v^{1}(0)$, the Cournot renter cannot plausibly commit itself to such a level. Even if it produced more than $\mathrm{V}^{1}(0)$ units in the first period, it will withhold any stock in excess of $V^{1}(0)$ from the market in the postentry equilibrium.

If the Stackelberg renter chooses to effectively impede entry, the Cournot renter will always be able to duplicate its strategy. Section V showed that this strategy will never involve production in the second period, nor withholding of output. If it produces $Q$ units in the first period, the Cournot renter will wish neither to produce any more, nor withhold any output, in the second period. Indeed, as Iong as $\mathrm{Z}^{1}>\mathrm{Q}$, the Cournot renter can effectively impede entry. And if such a strategy is optimal for the Stackelberg renter, $\mathrm{Z}^{1}>\mathrm{Q}$ must hold, as equation (31) shows.

Suppose the Stackelberg renter chooses to allow entry. Using the taxonomy of Section V, the Cournot renter's outcomes can then be classified as follows: 
Case A. $x_{1}^{1 *}<Q, x_{1}^{1 *}>s_{2}^{1 *}=\sigma^{1}\left(x_{1}^{1 *}\right)$. The Stackelberg renter withholds output. Since first-period production does not, at the margin, affect second-period profits, $x_{7}^{1 *}$ is chosen with regard to firstperiod profit alone. Thus $X_{1}^{1 *}=M^{1}$. Also $V^{1}(0)<s_{2}^{1 *}<M^{1}$. The Cournot renter also withholds, but sets $x_{1}^{1}=M^{1}, s_{2}^{1}=V^{1}(0)$ and therefore withholds more than the Stackelberg renter.

Case B. $\mathrm{x}_{1}^{1 *}<\mathrm{s}_{2}^{1 *}=\sigma^{1}\left(\mathrm{x}_{1}^{1 *}\right)$. The Stackelberg renter produces in the second period. As noted above, the Cournot renter cannot duplicate this strategy. Define $\bar{x}_{7}^{1}$ as the value of $x_{1}^{1}$ which maximizes

$$
\left[\phi\left(x_{1}^{1}\right)+\delta \phi\left(x_{1}^{1}+\gamma^{2}\left(x_{1}^{1}\right)\right)-c\right] x_{1}^{1}
$$

There are now three sub-cases to consider.

Sub-case B,1. $\bar{x}_{1}^{1}=Q, V^{1}(0)>Q$. In this case the Cournot renter chooses to effectively impede entry, even though the Stackelberg renter does not. It chooses $x_{1}^{1}=s_{2}^{1}=Q, x_{2}^{1}=0$.

Sub-case $B_{2} .2 \bar{X}_{1}^{1}<Q, v^{1}(0)>\bar{x}_{1}^{1}$. The Cournot renter allows entry, and rents all its output in each period. $x_{1}^{1}=s_{2}^{1}=\bar{x}_{1}^{1}$.

Sub-case B,3. $\bar{x}_{Y}^{1}<Q, v^{1}(0)<\bar{x}_{l}^{1}$. The Cournot renter allows entry, but faces a withholding problem. It sets $x_{1}^{1}=\max \left[M^{1}, v^{1}(0)\right], s_{2}^{1}=v^{1}(0)$.

Case C. $\mathrm{x}_{1}^{1 *}=\sigma^{1}\left(\mathrm{X}_{1}^{1 *}\right)$. The Stackelberg renter neither produces nor withholds in the second period. Again there are sub-cases to consider.

Sub-case C.1. $\mathrm{x}_{1}^{1 *} \leq \mathrm{v}^{1}(0)$. Here the Cournot renter can duplicate the Stackelberg solution.

Sub-case $C_{2} .2 x_{1}^{1 *}>V^{1}(0)$. The Cournot renter faces a withholding problem and cannot achieve the Stackelberg optimum. It $\operatorname{set} s \mathrm{x}_{1}^{1}=\max \left[\mathrm{M}^{1}, \mathrm{v}^{1}(0)\right], \mathrm{s}_{2}^{1}=\mathrm{v}^{1}(0)$. 
Table 4 presents closed-form solutions for the Cournot renter facing linear demand. Only case $C$ can occur. As can be seen, the Cournot renter's difficulties arise only when marginal cost $c$ is low relative to the demand curve's intercept $\alpha$. To see the intuition behind this, consider the extreme case where $c=0$. If production is costless, inventories are no advantage at all. The Cournot renter's second-period problem is exactly that of one of A. A. Cournot's original, one-period mineral-spring duopolists. The second-period and first-period production decisions are decoupled. Thus, as Table 4 shows, the established firm produces (and rents out) the 1-period monopoly output $\frac{\alpha}{2}$ in the first period, but only rents out $\frac{\alpha}{3}$ in the postentry Nash equilibrium. Of course this situation is inferior to the postentry Stackelberg situation, in which it would rent out all its first-period production (since 1-period monopoly and 1-period Stackelberg outputs coincide in this linear case).

Looking ahead, note also that when production is costless, the post-entry equilibrium will be different when the established firm can sell some of its first-period production. The equilibrium in the original A.A. Cournot example will be altered if some buyers have stocks of mineral water on hand. For instance, if the established firm had produced the 1-period monopoly output $\frac{\alpha}{2}$, and sold it all in the first period, then in the second period $s_{2}^{1}=s_{2}^{2}=\frac{\alpha}{6}$. As it happens, such a strategy yields identical profits to the established firm as the optimal Cournot-renter policy. But a better choice of $x_{y}^{1}$ can yield higher profits, as Sections VII and VIII will show. 
VII. ESTABLISHED COURNOT FIRM: THE CASE OF SELLING ONLY

In this section, it is assumed that firms are limited to contracts which transfer the right to all future usesi of the durable good. In the context of the model the effect of thisi limitation is to prevent the established firm from offering rental contracts in the first period. This limitation is of no consequence to the firm which can precommit. Although in Section $V$ it was convenient to assume the durable was rented, with precommitment the optimal precommitment revial plan can easily be translated into an equivalent sales plan, having no efifect except to alter the pattern of consumer expenditures without altering the present value of those expenditures as there is no effect on the pattern of services consumed. ${ }^{7}$ The established firm here will be assumed to be unable to explicitly precommit its second period sales. Contrary to the no-entry case where the monopolist preferred renting to selling, under the threat of entry selling can be the preferred contract.

The terminology in Section III emphasized the similarity between the seller's own behavior in the second period and that of a potential entrant. In fact, in any Nash equilibrium it must be true that $s_{2}^{2}=s_{2}^{1}$. It follows that the Cournot seller can achieve the precommitment optimum if and only if that optimum involves entry deterrence. Sufficiency is clear: entry deterrence requires $\mathrm{x}_{1}^{1} \leq \mathrm{Q}$, which certainly implies the Cournot seller will not find it profitable to produce anything more in the second period. In cases $A$ and $C$ it is also clear the Cournot seller cannot duplicate the optimal entry-allowing strategy. Since in each case $s_{2}^{1}=0$, 
and entry allowance implies $s_{2}^{2}>0$, the optimum cannot be the result of Cournot-type behavior by both sellers in the second period. In case B, the Stackelberg renter finds it optimal to set $s_{2}^{1}>0$. But the Cournot seller would not choose the correct positive $s_{2}^{1}$, given that it had produced the appropriate $x_{1}^{1}$ in the first period, as shown formally in the appendix.

Even if it is not optimal for the Stackelberg renter to deter entry, the Cournot seller may still do so. Near $x_{1}^{1}=Q$, a slight decrease in $x_{1}^{1}$ will increase both $s_{2}^{1}$ and $s_{2}^{2}$ by $1 / 3$ of the decrease. Hence the marginal added profit to the established seller of decreasing $x_{1}^{1}$ slightly below $Q$ is

$$
\begin{aligned}
{\left[\phi\left(x_{1}^{1}\right)\right.} & +x_{1}^{1} \phi^{\prime}\left(x_{1}^{1}\right)-c+\frac{\delta}{3} \phi^{\prime}\left(x_{1}^{1}+s_{2}^{1}+s_{2}^{2}\right)\left(x_{1}^{1}+s_{2}^{1}\right) \\
& \left.+\frac{\delta}{3}\left(\phi\left(x_{1}^{1}+s_{2}^{1}+s_{2}^{2}\right)-c\right)+\delta \phi\left(x_{1}^{1}+s_{2}^{1}+s_{1}^{1}\right)\right] .
\end{aligned}
$$

Since $\phi\left(x_{1}^{1}\right)=c$ and $s_{2}^{1}=s_{1}^{1}=0$ when $x_{1}^{1}=Q$, this expression is $-\frac{1}{3}\left[(3+\delta) Q \phi^{\prime}(Q)-3 c\right]$, and so entry should be deterred if

$$
(3+\delta) Q \phi^{\prime}(Q)+3 \delta c \geq 0 \text {. }
$$

Comparison of (40) and (30) shows the seller is more likely to deter entry than the renter, or the firm which can precommit.

When entry is allowed, the post-entry equilibrium is the symmetric Cournot-Nash equilibrium $T\left(X_{1}^{1}\right)$ defined in equation $(16)$. Since $T^{1}\left(X_{1}^{1}\right)=T^{2}\left(X_{1}^{1}\right)+X_{1}^{1}$ from the symmetry, the established firm's profits are

$$
\left(\phi\left(x_{1}^{1}\right)-c\right) x_{1}^{1}+\delta\left[\left(T^{2}\left(x_{1}^{1}\right)+X_{1}^{1}\right) \phi\left(x_{1}^{1}+2 T^{2}\left(x_{1}^{1}\right)\right)-c T^{2}\left(x_{1}^{1}\right)\right]
$$


Thus when $(3+\delta) Q \phi^{\prime}(Q)+3 \delta c<0$, the seller's optimal $x_{1}^{1}$ is defined by the first-order condition

$$
\begin{aligned}
\phi\left(\mathrm{x}_{1}^{1}\right) & +\mathrm{x}_{1}^{1} \phi^{\prime}\left(\mathrm{x}_{1}^{1}\right)-\mathrm{c}+\delta\left[\phi\left(\mathrm{x}_{1}^{1}+2 \mathrm{~T}^{2}\left(\mathrm{x}_{1}^{1}\right)\right)\left(\mathrm{T}+\mathrm{T}^{2}\left(\mathrm{x}_{1}^{1}\right)\right)\right. \\
& \left.+\left(\mathrm{x}_{1}^{1}+\mathrm{T}^{2}\left(\mathrm{x}_{1}^{1}\right)\right) \phi^{\prime}\left(\mathrm{x}_{1}^{1}+2 \mathrm{~T}^{2}\left(\mathrm{x}_{1}^{1}\right)\right)\left(1+2 \mathrm{~T}^{2^{\prime}}\left(\mathrm{x}_{1}^{1}\right)\right)-c \mathrm{~T}^{2}\left(\mathrm{x}_{1}^{1}\right)\right]=0
\end{aligned}
$$

Comparison of (41) with (33) shows that, at least in Case C, the seller will provide more of the services of the durable good in the first period than the firm which can precommit and a fortiori the renter. There will also be more services provided in the second period. As in the no-entry case, selling is "anti-competitor" but "pro-competitive" compared with renting or precommitment.

Table 5 presents the seller's optimum for the case of linear demand.

The discussion of the case $c=0$ at the end of Section VI showed selling was at least as profitable as rental. In fact, the results for the case of linear demand provided in Tables 4 and 5 can be used to compare explicitly the profitability of the two types of contracts for the established firm. If the further assumption is made that the future is important

$$
\delta=1
$$

then Table 4 shows the present value of profits from renting when $\alpha \geq 5 \mathrm{c}$ are

$$
\frac{1}{36 \beta}\left[13 \alpha^{2}-10 \alpha c+13 c^{2}\right]
$$

and Table 5 shows the profits from selling when $\alpha>\frac{7}{4}$ c are

$$
\frac{1}{44 \beta}\left[16 \alpha^{2}-12 \alpha c+5 c^{2}\right]
$$

Thus selling is more profitable if (and, it can be shown, only if) $\alpha^{2}-2 \alpha c-98 c^{2}<0$, or $\alpha>8.95 c$ (approximately). 
VIII. ESTABLISHED COURNOT FIRM: CONCURRENT RENTING AND SELLING

This section relaxes the constraints imposed in the last two sections on the types of contracts which can be offered. The established firm is allowed to rent and/or sell in the first period. Obviously, the ability to choose between renting and selling dominates being limited to either one or the other; as seen above, under threat of entry renting is in some cases better than selling and in other cases inferior. Less obvious is the result proven below that concurrent renting and selling will in some cases be better than only renting or only selling. Moreover, when renting and selling is allowed the established cournot firm can always effectively duplicate the precommitment plan.

The intuition behind this result is not too difficult to see. If the Cournot renter can duplicate the precommitment plan, obviously the firm which has a choice of renting and selling will choose to rent all output produced in the first period. Now suppose the Cournot renter cannot duplicate the precommitment plan, as discussed in section VI. The renter's problem is that it does not rent enough output in the second period. By behaving à la Cournot, it does not realize that any expansion of its own sales will reduce those of its rival by $\gamma^{2^{\prime}}$, thus mitigating the fall in second-period price. This problem, of course, arises in the simple static case, where a Cournot firm's equilibrium sales are less than those of a Stackelberg leader.

The Cournot seller has the same problem of ignoring its rival's reaction. But it has an offsetting problem. By ignoring the effect of its own second-period sales on the price of its first-period output it tends to expand second-period sales beyond the optimal level. This latter problem arises even without an entry threat. However, this latter 
"over-expansion" effect dominates the "under-expansion" effect due to playing Cournot. In cases $A$ and $C$ this result is obvious; the precommitment optimum involves no production in the second period. In Case B, the result is less obvious. However, in the appendix it is proved true. Let asterisks denote the precommitment optimum values of variables. If the seller produces and sells $\mathrm{x}_{1}^{1 *}$ units in the first period, and its rival produces and sells $s_{2}^{2 *}=\gamma^{2}\left(x_{1}^{1 *}+s_{2}^{1 *}\right)$ in the second period, then the seller will wish to produce and sell more than $\mathrm{S}_{2}^{1 *}$ units in the second period.

Consider now the firm that has the option of concurrently renting and selling. If it produces $x_{1}^{1 *}$ units in the first period, and sells them a11, it will produce too much output (or the correct amount) in the second period if its rival sells $s_{2}^{2 *}$. If it produces $x_{1}^{1 *}$ units and sells none, it will sell too little output (or the correct amount) if its rival sells $\mathrm{s}_{2}^{2 *}$. Since all second-period variables are continuous in $\mathrm{s}_{1}^{1}$, there must therefore always be some $0 \leq s_{1}^{1 *} \leq x_{1}^{1}$ such that if the established firm produces $x_{1}^{1 *}$ and sells $s_{1}^{1 *}$ of them, then the next period's Cournot-Nash equilibrium sales will be $\left(\mathrm{s}_{2}^{1 *}, \mathrm{~s}_{2}^{2 *}\right)$. The discussion below characterizes this optimal policy for the different cases. It should be repeated that when demand is linear, only case $C$, the simplest case, can arise.

Consider each of the precommitment cases once more. Case A. $\mathrm{x}_{1}^{1 *}>\sigma^{1}\left(\mathrm{x}_{1}^{1 *}\right)$. Neither the Cournot renter nor the Cournot seller can duplicate the precommitment rental plan

$$
\left\{\begin{array}{l}
\mathrm{Y}_{1}^{1 *}=\mathrm{x}_{1}^{1 *}=\mathrm{M}^{1} \\
\mathrm{~s}_{2}^{1 *}=\tilde{\sigma}^{1}(0)
\end{array}\right.
$$

or its sales equivalent. However, concurrent renting and selling by the cournot firm can. First-period production must of course equal $M^{1}$. If this is all rented, we have seen that the established firm's second-period 
sales will equal $v^{1}(0)<\tilde{\sigma}^{1}(0)$. Likewise, if this is all sold, then production will take place in the second period. However, $v^{1}\left(s_{1}^{1}\right)$ is an increasing function of $s_{1}^{1}$. Thus, the established cournot firm should sell $s_{1}^{1}=s_{1}^{1 * *}$ where $s_{1}^{1}=s_{1}^{1 * * *}$ satisfies $\tilde{\sigma}^{1}(0)=v^{1}\left(s_{1}^{1}\right)$.

First-period rentals by the established Cournot firm $Y_{1}^{1}=Y_{1}^{1 * *}$ satisfy

$$
\mathrm{Y}_{1}^{1}=\mathrm{M}^{1}-\mathrm{s}_{1}^{1 * *}
$$

This is illustrated in Figure 6. The established firm will not produce in the second period: $T^{1}\left(S_{1}^{1 * *}\right)<M^{1}-S_{1}^{1 * *}$.

Case B. $\mathrm{x}_{1}^{1 *}<\sigma^{1}\left(\mathrm{x}_{1}^{1 *}\right)$. The precommitment rental plan is

$$
\left\{\begin{array}{l}
\mathrm{Y}_{1}^{1 *}=\mathrm{X}_{1}^{1 *}=\mathrm{E}^{1} \\
\mathrm{~s}_{2}^{1 *}=\tilde{\sigma}^{1}(\mathrm{c}) .
\end{array}\right.
$$

Since it can be shown there always exist an $s_{1}^{1 * *}<x_{1}^{1 *}$ such that $s_{1}^{1}=s_{1}^{1 * *}$ satisfies

$$
\tilde{\sigma}^{1}(c)=T^{1}\left(s_{1}^{1}\right)
$$

the Cournot firm can effectively duplicate this plan by choosing $s_{1}^{1}$ to satisfy (42). Since $s_{1}^{1}$, strictly less than $x_{1}^{1 *}$ satisfies (42), selling only cannot duplicate precommitment in this case. The established cournot firm's plan is

$$
\left\{\begin{array}{l}
x_{1}^{1}=E^{1} \\
s_{1}^{1}=s_{1}^{1 * *} \\
y_{1}^{1}=x_{1}^{1}-s_{1}^{1 * *} \\
s_{2}^{1 * *}=\tilde{\sigma}^{1}(c)-s_{1}^{1 * *}
\end{array}\right.
$$

This is illustrated in Figure 7. 
Case c. $x_{1}^{1 *}=\sigma^{1}\left(x_{1}^{1 *}\right)$. Recall from the discussion in Section VI, Sub-case $\mathrm{C} 1$, that if $\mathrm{x}_{1}^{1 *}<\mathrm{V}^{1}(0)$ the Cournot renter could duplicate precommitment. However, if as in Sub-case $c 2, x_{1}^{1 *}>v^{1}(0)$, then the Cournot renter had a withholding problem; he could not effectively commit to selling more than $\mathrm{V}^{1}(0)$. By selling some of $\mathrm{x}_{1}^{1 *}$ in the first period the established Cournot firm can raise its second-period marginal revenue easing the withholding problem. By producing $x_{1}^{1 *}$ and selling $s_{1}^{1}=s_{1}^{1 * *}$ satisfying $\mathrm{x}_{1}^{1 * *}=\mathrm{v}\left(\mathrm{s}_{1}^{1}\right)$

the precommitment plan can be duplicated. Such an $s_{1}^{1 * *} \leq x_{1}^{1 *}$ always exists. Figure 8 illustrates.

We have proven

Theorem:

(i) When the established firm follows Cournot behavior in the post-entry period, the freedom to determine both the quantity of the good it produces in the first period and the ratio of first-period sales to first-period rentals is sufficient to make the precommitment plan feasible even in the absence of precommitment.

(ii) Under the threat of entry, and in the absence of the ability to precommit, selling can be preferred to renting. Moreover, for sufficiently small c concurrent renting and selling will be optimal.

Table 6 presents the linear demand results. 
IX. WHEN ENTRY DRIVES PRICE DOWN TO MARGINAL COST

When entry is allowed, the entrant earns positive profit. Since there are constant average costs, there are no barriers to entry explicit in the mode1. In essence it has been assumed thus far that entry fees for every potential entrant beyond the first are sufficiently large to create a barrier to entry. Suppose that there are no such entry fees. Suppose also there is an infinite number of potential entrants. Then the second-period price must be driven down to marginal cost $c$ if entry is not blockaded, and if the post-entry game is cournot. For each entrant will make positive profit in Cournot-Nash equilibrium when there are $n+1$ entrants. Hence there is no finite industry size such that a rational $(n+1)$-st entrant would not also wish to enter. of course the post-entry equilibrium, when price equals marginal cost, will involve an infinite number of firms and indeterminate firm size. But this phenomenon is inevitable when there are constant returns to scale, and does not preclude the existence of a well-posed maximization problem for the established firm. The seller has no incentive (but no disincentive) to produce in the second period; the entry threat now guarantees the second-period price will be min $\left(c, \phi\left(x_{1}^{1}\right)\right)$ regardless of the sales to rental ratio in the first period.

The present value of the established firm can be written

$$
\left\{\begin{array}{lc}
\left(\phi\left(\mathrm{x}_{1}^{1}\right)-c\right) \mathrm{x}_{1}^{1}+\delta c \mathrm{x}_{1}^{1} & \text { if } \phi\left(\mathrm{x}_{1}^{1}\right)<c \\
\left(\phi\left(\mathrm{x}_{1}^{1}\right)-c\right) \mathrm{x}_{1}^{1}+\delta \phi\left(\mathrm{x}_{1}^{1}\right) \mathrm{x}_{1}^{1} & \text { if } \phi\left(\mathrm{x}_{1}^{1}\right)<c
\end{array}\right\} .
$$

The optimal plan is: 


\section{(1) Blockaded Entry:}

If $(1+\delta)\left(\phi(Q)+Q \phi^{\prime}(Q)\right)-c \geq 0$, then $(1+\delta)\left(\phi\left(x_{1}^{1}\right)+x_{1}^{1} \phi^{\prime}\left(x_{1}^{1}\right)-c=0\right.$;

(ii) Effectively Impeded Entry:

If $\phi(Q)+Q \phi^{\prime}(Q)-(1-\delta) c \geq 0>(1+\delta)\left(\phi(Q)+Q \phi^{\prime}(Q)\right)-c$; then $\mathrm{X}_{1}^{1}=\mathrm{Q}$.

(iii) Ineffectively Impeded Entry:

If $\phi(Q)+Q \phi^{\prime}(Q)-(1-\delta) c<0$, then $\phi\left(\mathrm{x}_{1}^{1}\right)+\mathrm{x}_{1}^{1} \phi^{\prime}\left(\mathrm{x}_{1}^{1}\right)-(1-\delta) c=0$

As might be expected there is more incentive to flood the market to deter entry when entry drives price down to marginal cost. Table 7 presents the linear demand case.

\section{CONCLUSION}

The main questions examined in this paper are (i) how the producer of a durable good will alter production in the face of entry; and (ii) how it will alter the types of contracts it makes with consumers.

Output prior to entry will be at least as large as that produced by the monopolist in the absence of an entry threat. In some circumstances the entry threat may induce the established firm to so flood the market prior to entry as to prevent entry. The expansion of output in the fact of an entry threat might be interpreted as predatory pricing. But unlike many models of predatory pricing all the agents here are rational. Moreover, this expansion benefits consumers.

In the absence of the threat of entry, renting makes it feasible to achieve the precommitment optimum. Indeed, the monopolist who can do so will not sell its product thereby avoiding the creation of an incentive to overproduce (the Coase problem). In the presence of the threat of 
entry, the monopolist which can only rent its output may not necessarily achieve the precommitment optimum, if the post-entry game is Cournot. The monopolist which can only sell its output also may not achieve this optimum. But it may do better than the renter, if production costs are low enough. Its incentive to overproduce is mitigated by the tendency of a Cournot firm to produce less than a Stackelberg leader would find optimal. And if the established firm can concurrently rent and sell prior to entry, it can always achieve the precommitment optimum, even if it behaves as a cournot duopolist after entry. Finally, if the number of entrants is large enough to drive the post-entry price down to marginal cost, then the renter/seller distinction is of no significance. 


\section{FOOTNOTES}

${ }^{1}$ See also, Flath (1980), and Stokey (1981).

${ }^{2}$ See, for instance, Salop (1978), Spulber (1981), and Dixit (1982).

${ }^{3}$ Ware (1982) demonstrates how an inventory of a storable, but nondurable good can also be used as a strategic variable.

${ }^{4}$ Flath (1980) provides competitive explanations for concurrent renting and selling. Interestingly he claims (p. 259), "...the [monopoly] explanations [are not] consistent with concurrent leasing and selling markets for perfect substitutes."

${ }^{5}$ This result follows from equation (7), and the fact that $x=\gamma^{2}$. 7 Osbo:ne (1973). py 77 projes this as well.

The ability to buy back under precommitment has been assumed here.

See Case 1 of Section V. Of course the ability to commit to a buy-back makes renting/selling distinctions vacuous.

8 Although Porter (1983) shows predatory pricing can benefit consumers as we11. 
APPENDIX: Proof that renting/selling achieves the Stackelberg optimum in Case B.

From Section $\mathrm{V}$ the optimum satisfies :

$$
\begin{aligned}
& \phi\left(E^{1}\right)+E^{1} \phi^{\prime}\left(E^{1}\right)=(1-\delta) c \\
& \phi\left(E^{1}+x_{2}^{1}+\gamma^{2}\left(E^{1}+x_{2}^{\prime}\right)\right)+\left(E^{1}+x_{2}^{1}\right) \phi^{\prime}\left(E^{1}+x_{2}^{\prime}+\gamma^{2}\left(E^{1}+x_{2}^{1}\right)\left(1+\gamma^{2^{\prime}}\left(E^{1}+x_{2}^{x}\right)\right)=c\right.
\end{aligned}
$$

where $\mathrm{E}^{1}=\mathrm{x}_{1}^{1}$.

Let $0 \leq \mathrm{S} \leq \mathrm{E}^{1}$ be quantity sold in period 1 . Then if the entrant produces $\bar{s}_{2}^{2}=\gamma^{2}\left(E^{1}+x_{2}^{d}\right)$, the established firm chooses $x_{2}^{1}$ to

$\operatorname{maximize}\left(\mathrm{x}_{2}^{1}+\left(\mathrm{E}^{1}-\mathrm{s}\right)\right) \phi\left(\mathrm{x}_{2}^{1}+\mathrm{E}^{1}+\bar{s}_{2}^{2}\right)-c \mathrm{x}_{2}^{1}$

subject to $\mathrm{x}_{2}^{1} \geq 0$

yielding first-order conditions

(34') $\phi\left(E^{1}+x_{2}^{1}+\bar{s}_{2}^{2}\right)+\left(x_{2}^{1}+\left(E^{1}-s\right)\right) \phi^{\prime}\left(x_{2}^{1}+E^{1}+\vec{s}_{2}^{2}\right)=c$

What is required is a level of $s$ such that $x_{2}^{1}$ satisfies both (34) and (34').

First, note that $S=0$ implies the left-hand side of (34') is less than $c$ at $x_{2}^{1}$, since $\gamma^{\prime}<0$. This result just confirms that the cournot renter will not wish to produce in period 2 .

Thus, it is sufficient to show the left-hand side of (34') exceeds $c$ at $E^{1}=S$, since everything is nice and continuous.

Now $-\frac{1}{2} \leq \gamma^{2^{\prime}} \leq 0$, so that if $\mathrm{E}^{1} \geq \mathrm{x}_{2}^{1}$ the result is proved.

But suppose $E^{1}<x_{2}^{1}$. Then (34), and the fact that $-\frac{1}{2} \leq \gamma^{2^{\prime}} \leq 0$ imply

(34") $\phi\left(E^{1}+x_{2}^{1}+\bar{s}_{2}^{2}\right)+E^{1} \phi^{\prime}\left(E^{1}+x_{2}^{1}+\bar{s}_{2}^{2}\right)>c$

From the fact that $\phi^{\prime}, \phi^{\prime \prime}<0$, then

(34"') $\phi\left(E^{1}\right)+E^{1} \phi^{\prime}\left(E^{1}\right)>c$

which clearly contradicts (33). 
Hence two results have been shown:

(i) The Cournot seller cannot duplicate the precommitment optimum in Case B.

(ii) There is some renting/selling combination which enables the established firm to achieve, in Case B, the precommitment optimum when the postentry game is Cournot. 
Table 1

Monopolist Renter, Monopoly with Precommitment

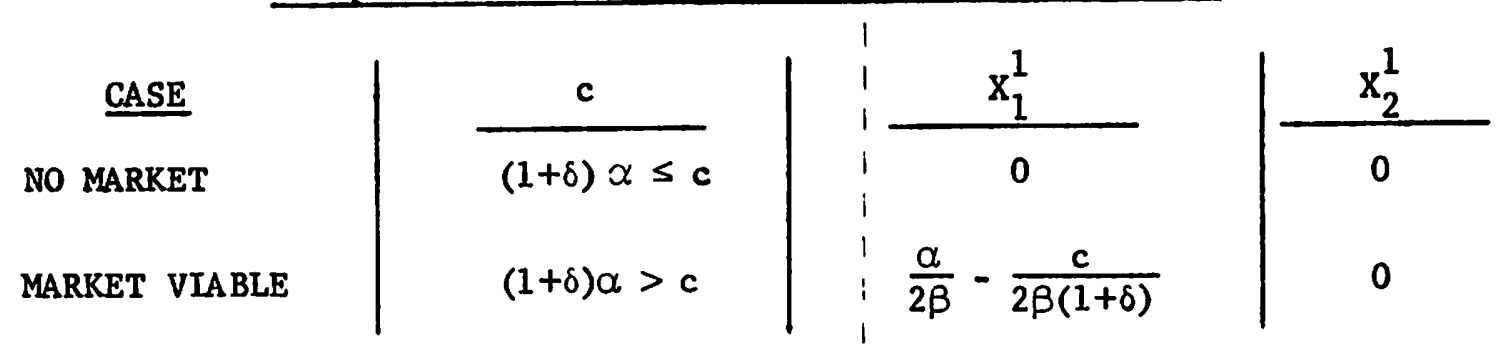

Table 2

Monopolist Seller

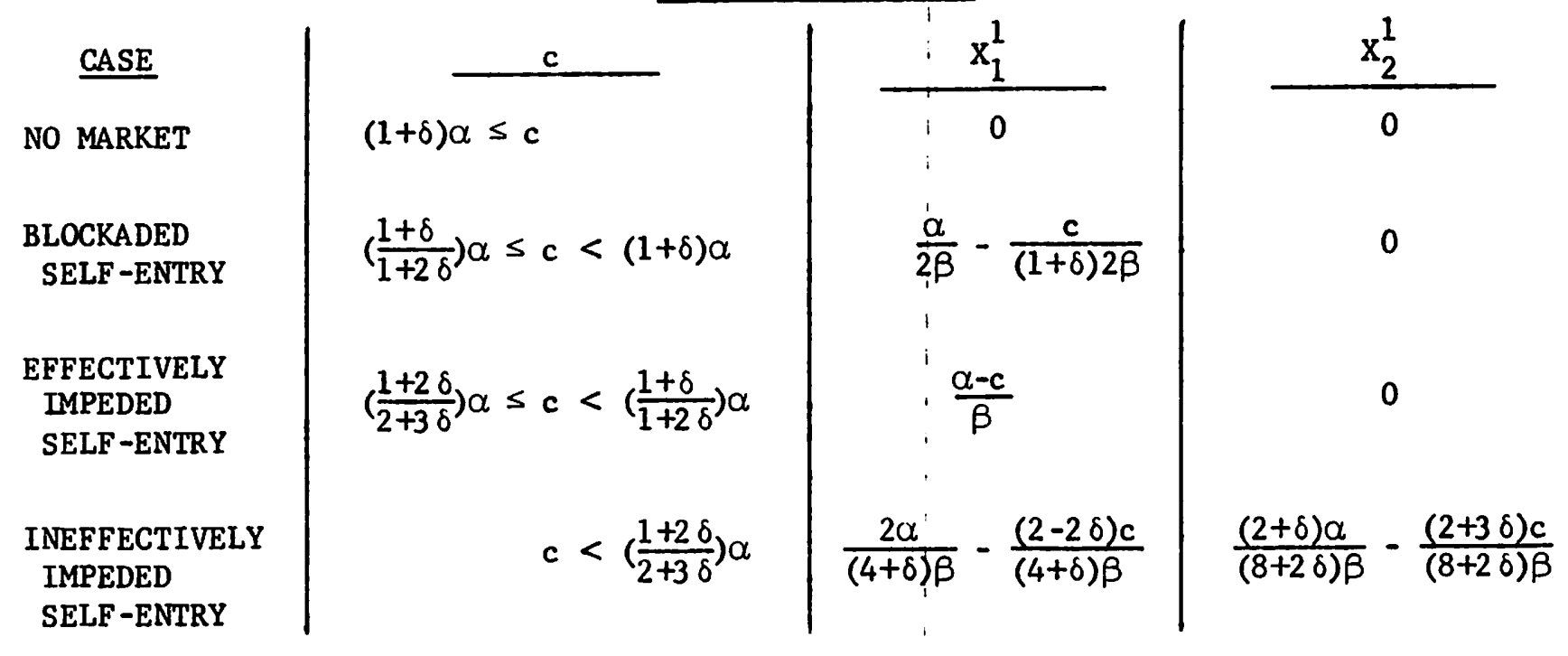

Table 3 .

Precommitment (Stackelberg Renter) Under Threat of Entry

\begin{tabular}{|c|c|c|c|c|}
\hline CASE & c & $\mathrm{Y}_{1}^{1}=\mathrm{X}_{1}^{1}$ & $s_{2}^{1}=Y_{1}^{1}+x_{2}^{1}$ & $s_{2}^{2}=x_{2}^{2}$ \\
\hline NO MARKET & $(1+\delta) \alpha \leq c$ & 0 & 0 & 0 \\
\hline $\begin{array}{l}\text { BLOCKADED } \\
\text { ENTRY }\end{array}$ & $\left(\frac{1+\delta}{1+2 \delta}\right) \alpha \leq \mathrm{c} \leq(1+\delta) \alpha$ & $\frac{\alpha}{2 \beta}-\frac{c}{(1+\delta) 2 \beta}$ & $\frac{\alpha}{2 \beta}-\frac{c}{(1+\delta) 2 \beta}$ & 0 \\
\hline $\begin{array}{l}\text { EFFECTIVELY } \\
\text { IMPEDED } \\
\text { ENTRY }\end{array}$ & $\left(\frac{2+\delta}{2+3 \delta}\right) \alpha \leq c<\left(\frac{1+\delta}{1+2 \delta}\right) \alpha$ & $\frac{\alpha-c}{\beta}$ & $\frac{\alpha-c}{\beta}$ & 0 \\
\hline $\begin{array}{l}\text { INEFFECTIVELY } \\
\text { IMPEDED } \\
\text { ENTRY }\end{array}$ & $c<\left(\frac{2+\delta)}{2+3 \delta)}\right) \alpha$ & $\frac{\alpha}{2 \beta}-\frac{(2-\delta) c}{(2+\delta) 2 \beta}$ & $\frac{\alpha}{2 \beta}-\frac{(2-\delta) c}{(2+\delta) 2 \beta}$ & $\frac{\alpha}{4 \beta}-\frac{(2+3 \delta) c}{(2+\delta) 4 \beta}$ \\
\hline
\end{tabular}


Table 4

Cournot Renter Equilibrium

\begin{tabular}{|c|c|c|c|c|}
\hline CASE & c & $\mathrm{Y}_{1}^{1}=\mathrm{x}_{1}^{1}$ & $\mathrm{~s}_{2}^{1}$ & $\mathrm{~s}_{2}^{2}$ \\
\hline NO MARKET & $(1+\delta) \alpha \leq c$ & $\begin{array}{ll}0 & i \\
i\end{array}$ & 0 & 0 \\
\hline $\begin{array}{l}\text { BLOCKADED } \\
\text { ENTRY }\end{array}$ & $\left(\frac{1+\delta}{1+2 \delta}\right) \alpha \leq c \leq(1+\delta) \alpha$ & $\frac{\alpha}{2 \beta}-\frac{c^{\prime}}{(1+\delta) 2 \beta}$ & $\frac{\alpha}{2 \beta}-\frac{c}{(1+\delta) 2 \beta}$ & 0 \\
\hline $\begin{array}{l}\text { EFFECTIVELY } \\
\text { IMPEDED } \\
\text { ENTRY }\end{array}$ & $\left(\frac{2+\delta}{2+3 \delta}\right) \alpha \leq c<\left(\frac{1+\delta}{1+2 \delta}\right) \alpha$ & $\frac{\alpha-c}{\beta}:$ & $\frac{\alpha-c}{\beta}$ & 0 \\
\hline $\begin{array}{l}\text { INEFFECTIVELY } \\
\text { IMPEDED } \\
\text { ENTRY I }\end{array}$ & $\left(\frac{2+\delta}{10-\delta}\right) \alpha \leq c<\left(\frac{2+\delta}{2+3 \delta}\right) \alpha$ & $\frac{\alpha}{2 \beta}-\frac{(2-\delta) c}{(2+\delta) 2 \beta}$ & $\frac{\alpha}{2 \beta}-\frac{(2-\delta) c}{(2+\delta) 2 \beta}$ & $\frac{\alpha}{4 \beta}-\frac{(2+3 \delta) c}{(2+\delta) 4 \beta}$ \\
\hline $\begin{array}{l}\text { INEFFECTIVELY } \\
\text { IMPEDED } \\
\text { ENTRY II }\end{array}$ & $\frac{\alpha}{5} \leq c \leq\left(\frac{2+\delta}{10-\delta}\right) \alpha$ & $\frac{\alpha+c}{3 \beta}:$ & $\frac{\alpha+c}{3 \beta}$ & $\frac{\alpha-2 c}{3 \beta}$ \\
\hline $\begin{array}{l}\text { INEFFECTIVELY } \\
\text { IMPEDED } \\
\text { ENTRY III, } \\
\text { OUTPUT } \\
\text { WITHHELD }\end{array}$ & $c<\frac{\alpha}{5}$ & $\frac{\alpha-c}{2 \beta}:$ & $\frac{\alpha+c}{3 \beta}$ & $\frac{\alpha-2 c}{3 \beta}$ \\
\hline
\end{tabular}


Table 5

Cournot Seller Equilibrium

\begin{tabular}{|c|c|c|c|c|}
\hline CASE & c & $s_{1}^{1}=x_{1}^{1}$ & $\mathrm{~s}_{2}^{1}$ & $\mathrm{~s}_{2}^{2}$ \\
\hline NO MARKET & $(1+\delta) \alpha \leq c$ & 0 & 0 & 0 \\
\hline $\begin{array}{l}\text { BLOCKADED } \\
\text { ENTRY I }\end{array}$ & $\left(\frac{1+\delta}{1+2 \delta}\right) \alpha \leq c \leq(1+\delta) \alpha$ & $\frac{\alpha}{2 \beta}-\frac{c}{(1+\delta) 2 \beta}$ & 0 & 0 \\
\hline $\begin{array}{l}\text { BLOCKADED } \\
\text { ENTRY II }\end{array}$ & $\left(\frac{2+\delta}{2+3 \delta}\right) \alpha \leq c \leq\left(\frac{1+\delta}{1+2 \delta}\right) \alpha$ & $\frac{\alpha-c}{\beta}$ & 0 & 0 \\
\hline $\begin{array}{l}\text { EFFECTIVELY } \\
\text { IMPEDED } \\
\text { ENTRY }\end{array}$ & $\left(\frac{3+\delta}{3+4 \delta}\right) \alpha \leq c \leq\left(\frac{2+\delta}{2+3 \delta}\right) \alpha$ & $\frac{\alpha-c}{\beta}$ & 0 & 0 \\
\hline $\begin{array}{l}\text { INEFFECTIVELY } \\
\text { IMPEDED } \\
\text { ENTRY }\end{array}$ & $\cdots-\cdots \leq\left(\frac{3+\delta}{3+4 \delta}\right) \alpha$ & $\frac{(9+\delta) \alpha}{(9+2 \delta) 2 \beta}-\frac{(9-8 \delta) c}{(9+2 \delta) 2 \beta}$ & $-\left(\frac{3+\delta}{9+2 \delta}\right)-\frac{\alpha}{2 \beta}--\left(\frac{3+4 \delta}{9+2 \delta}\right) \cdot \frac{c}{2 \beta}-$ & $-\left(\frac{3+\delta}{9+2 \delta}\right)-\frac{\alpha}{2 \beta}--\left(\frac{3+4 \delta}{9+2 \delta}\right)-\frac{c}{2 \beta} \ldots$ \\
\hline
\end{tabular}


Table 6

\begin{tabular}{|c|c|c|c|c|c|}
\hline CASE & $c$ & $x_{1}^{1}$ & $\mathrm{Y}_{1}^{1}=\mathrm{s}_{2}^{1}$ & $\mathrm{~s}_{1}^{1}$ & $\mathrm{~s}_{2}^{1}$ \\
\hline NO MARKET & $(1+\delta) \alpha \leq c$ & 0 & 0 & 0 & 0 \\
\hline $\begin{array}{l}\text { BLOCKADED } \\
\text { ENTRY }\end{array}$ & $\frac{(1+\delta)}{(1+2 \delta)} \alpha \leq c \leq(1+\delta) \alpha$ & $\frac{\alpha}{2 \beta}-\frac{c}{(1+\delta) 2 \beta}$ & $\frac{\alpha}{2 \beta}-\frac{c}{(1+\delta) 2 \beta}$ & 0 & 0 \\
\hline $\begin{array}{l}\text { EFFECTIVELY } \\
\text { IMPEDED } \\
\text { ENTRY }\end{array}$ & $\left(\frac{2+\delta}{2+3 \delta}\right) \alpha \leq c \leq\left(\frac{1+\delta}{1+2 \delta}\right) \alpha$ & $\frac{\alpha-c}{\beta}$ & $\frac{\alpha-c}{\beta}$ & 0 & 0 \\
\hline $\begin{array}{l}\text { INEFFECTIVELY } \\
\text { IMPEDED } \\
\text { ENTRY I }\end{array}$ & $\left(\frac{2+\delta}{10-\delta}\right) \alpha \leq c \leq\left(\frac{2+\delta}{2+3 \delta}\right) \alpha$ & $\frac{\alpha}{2 \beta}-\frac{(2-\delta) c}{(2+\delta) 2 \beta}$ & $\frac{\alpha}{2 \beta}-\frac{(2-\delta) c}{(2+\delta) 2 \beta}$ & 0 & $\frac{\alpha}{4 \beta}-\frac{(2+3 \delta) c}{(2+\delta) 4 \beta}$ \\
\hline $\begin{array}{l}\text { INEFFECTIVELY } \\
\text { IMPEDED } \\
\text { ENTRY II, III }\end{array}$ & $c \leq\left(\frac{2+\delta}{10-\delta}\right) \alpha$ & $\frac{\alpha}{2 \beta}-\frac{(2-\delta) c}{(2+\delta) 2 \beta}$ & $\frac{\alpha}{4 \beta}+\frac{(6+\delta) c}{(2+\delta) 4 \beta}$ & $\frac{\alpha}{4 \beta}-\frac{(10-\delta) c}{(2+\delta) 4 \beta}$ & $\frac{\alpha}{4 \beta}-\frac{(2+3 \delta) c}{(2+\delta) 4 \beta}$ \\
\hline
\end{tabular}


Table 7

\section{Entry Drives Price to Marginal Cost}

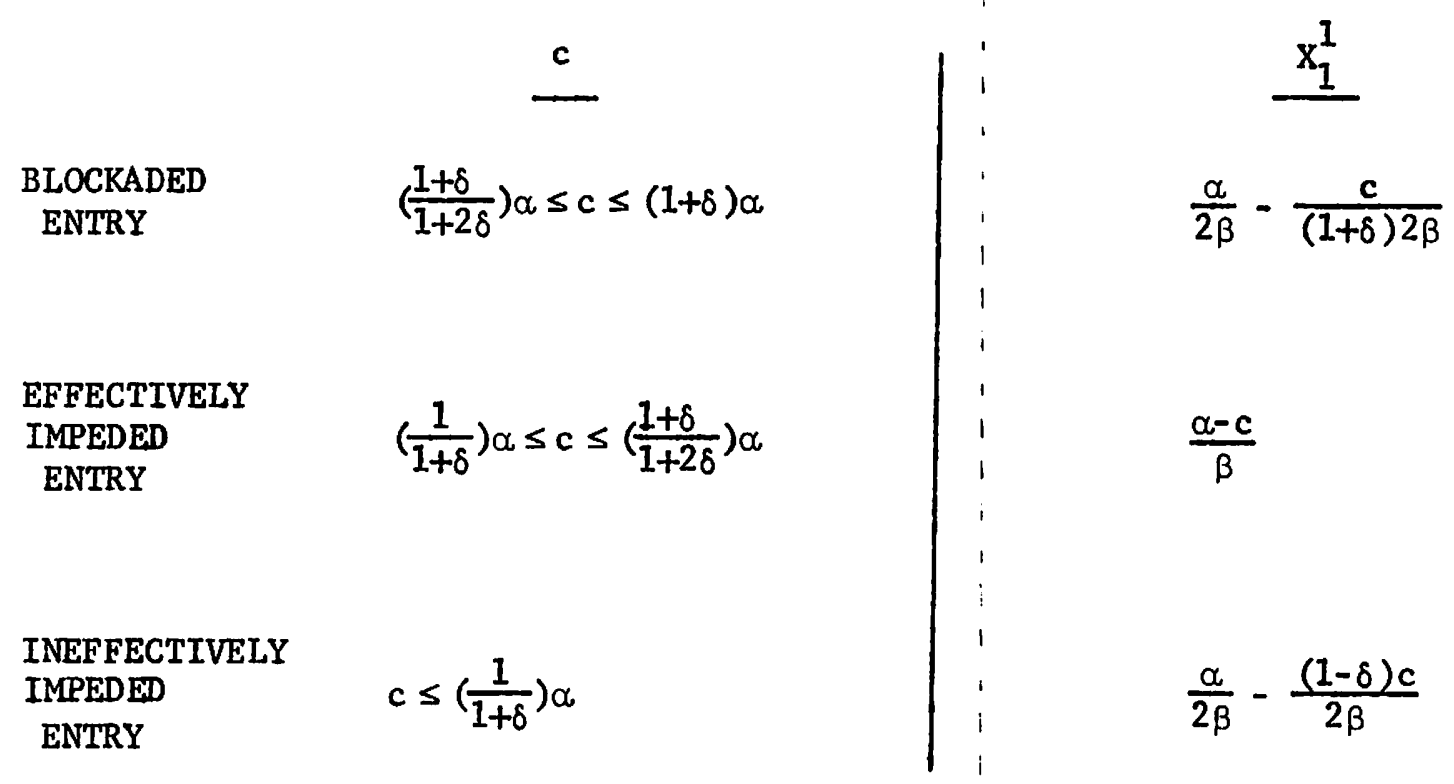




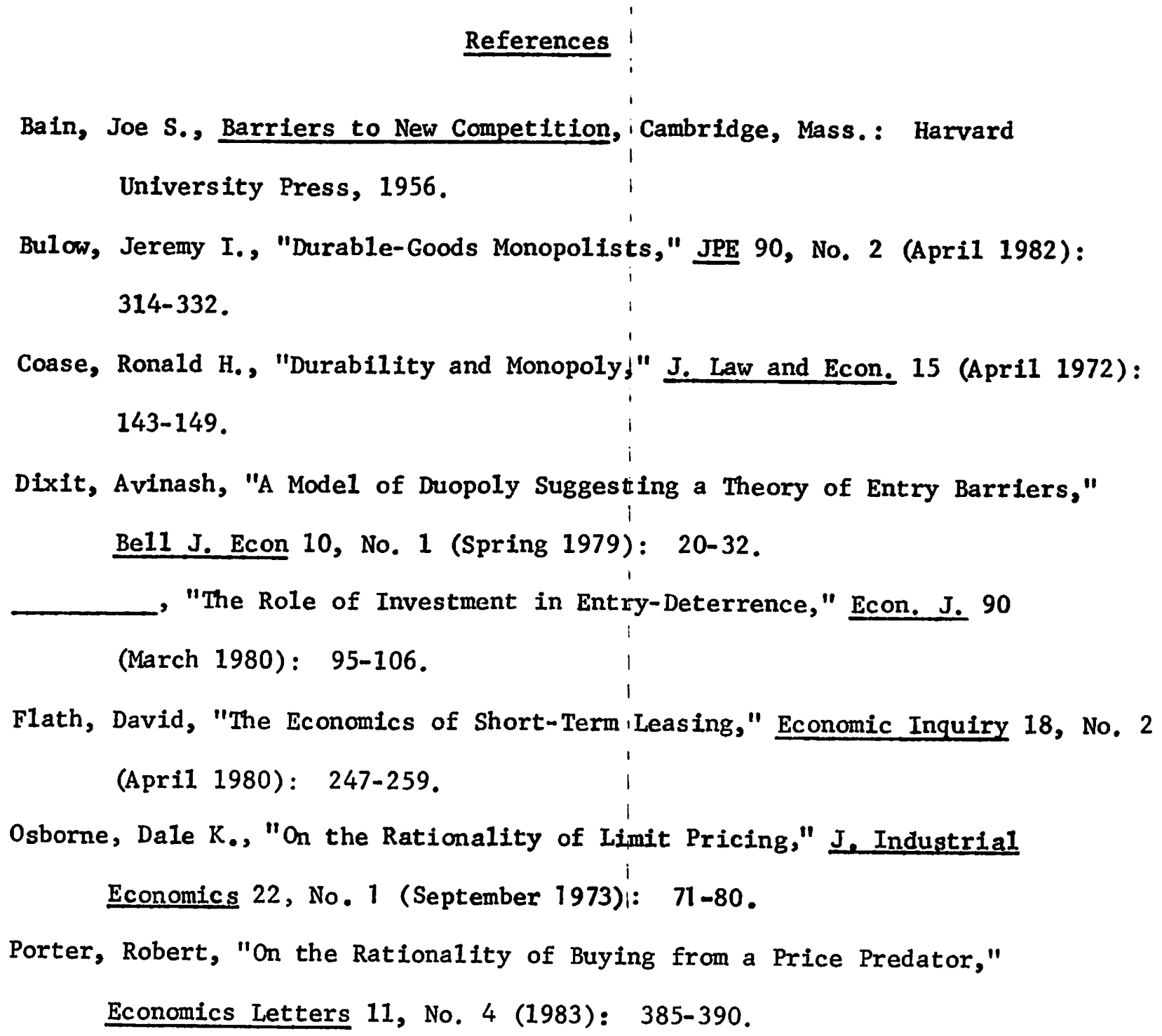

Stokey, Nancy L., "Rational Expectations and Durable Goods Pricing," Be11 J. Econ. 12, No. 1 (Spring 1981): 112-128.

Ware, Roger, "Inventory Holding as a Strategic Weapon to Deter Entry," Working Paper No. 8301, University of Toronto, Department of Economics (December 1982). 


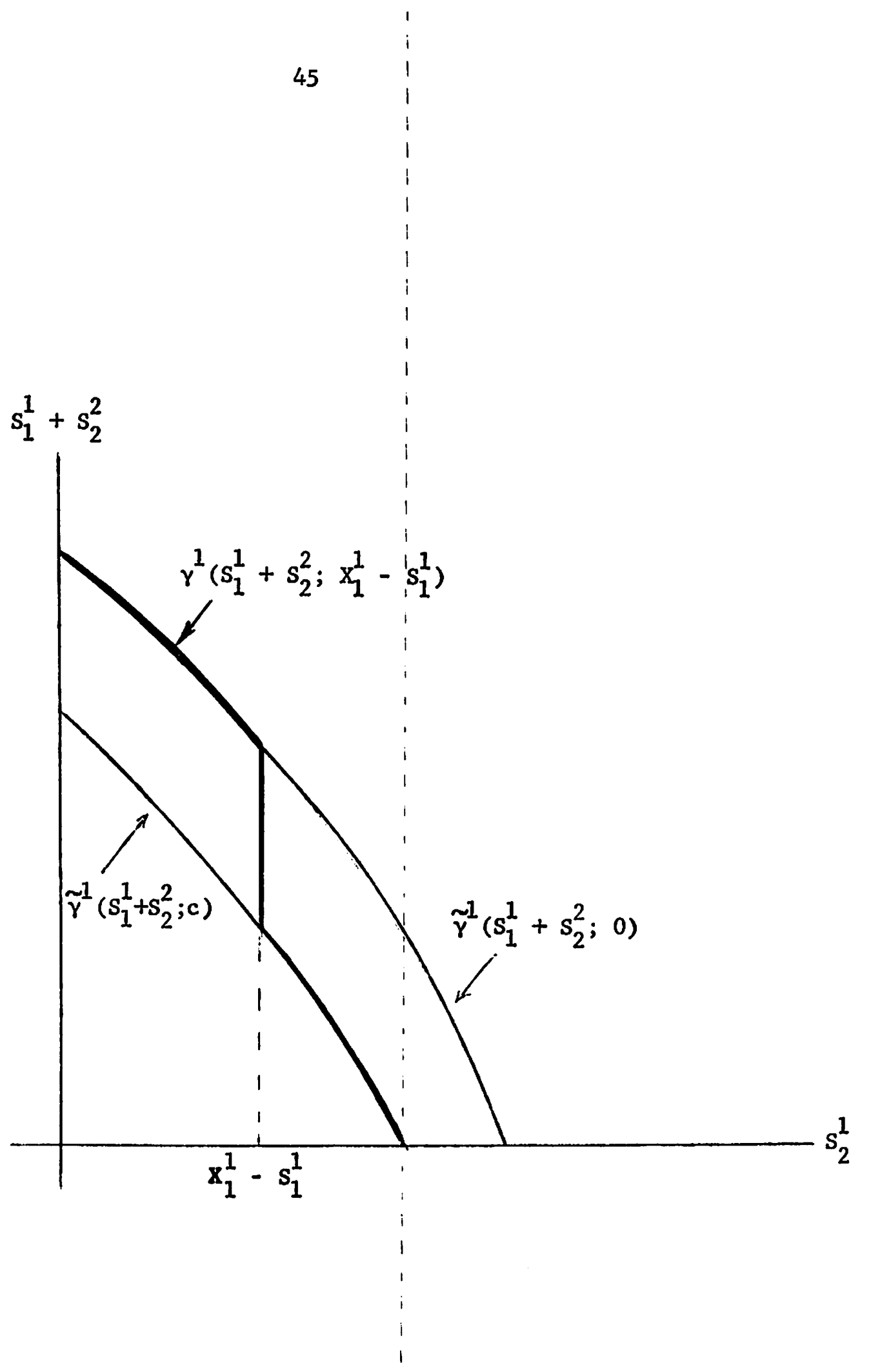

Figure 1 


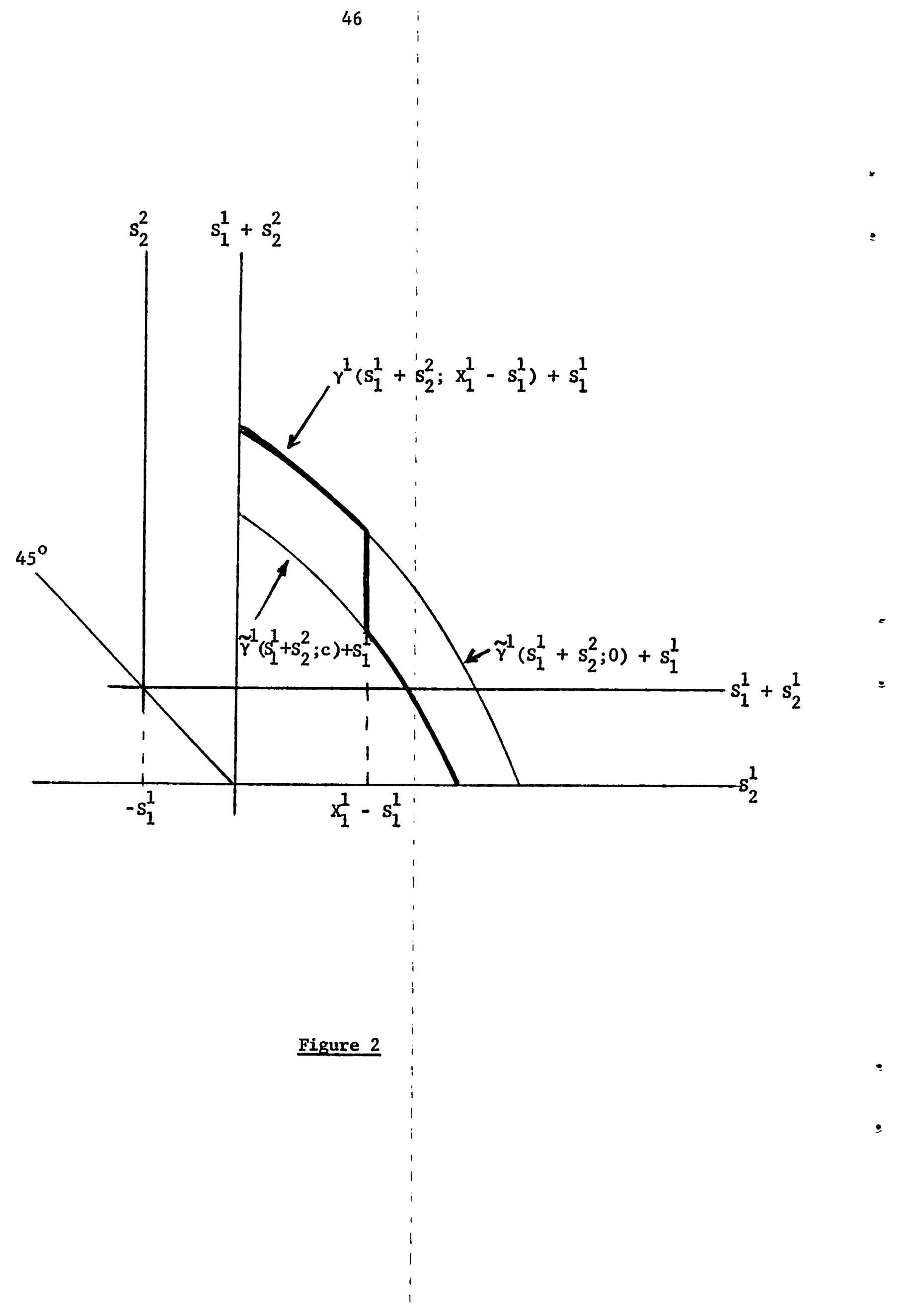




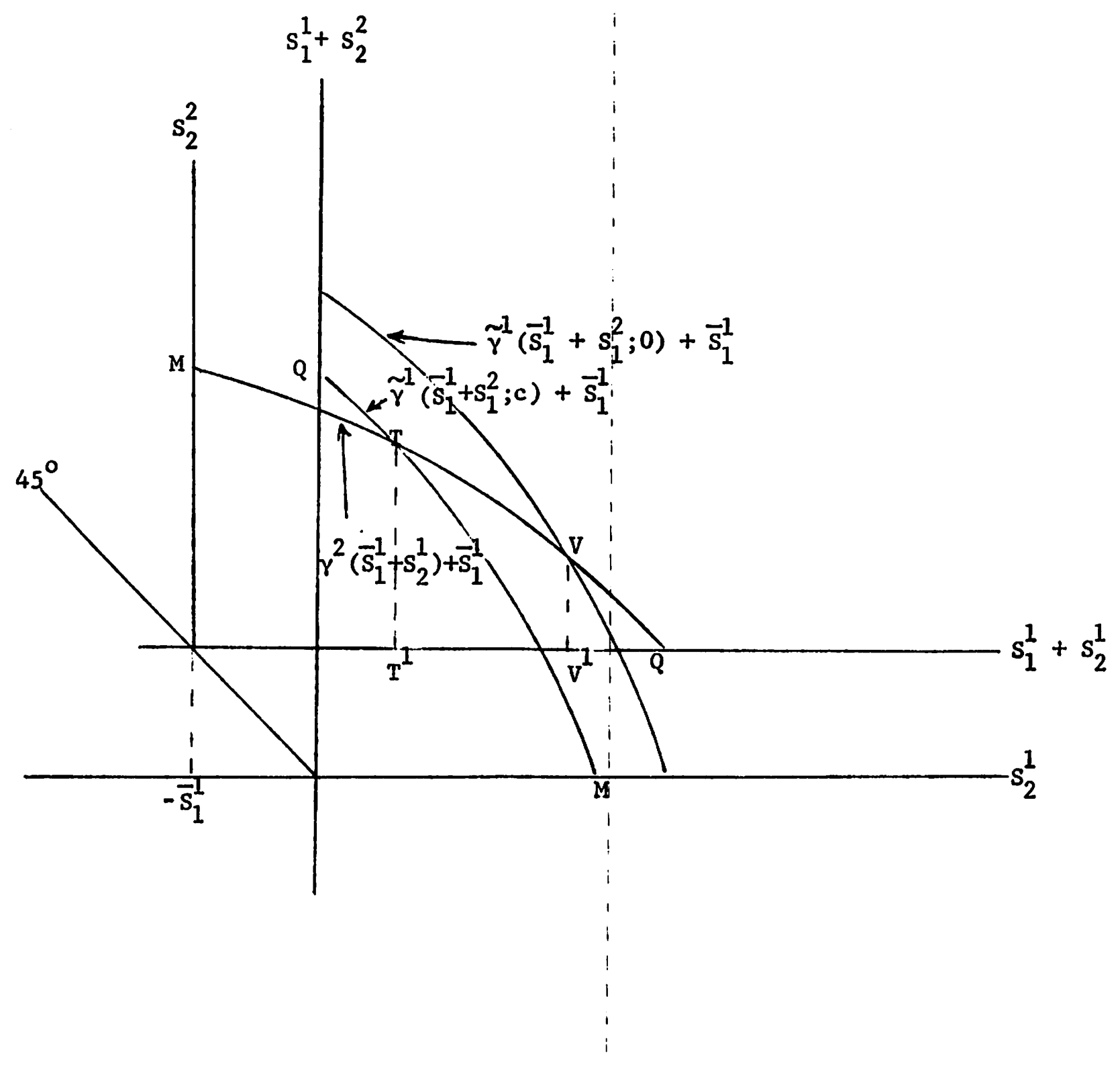

\section{Figure 3}




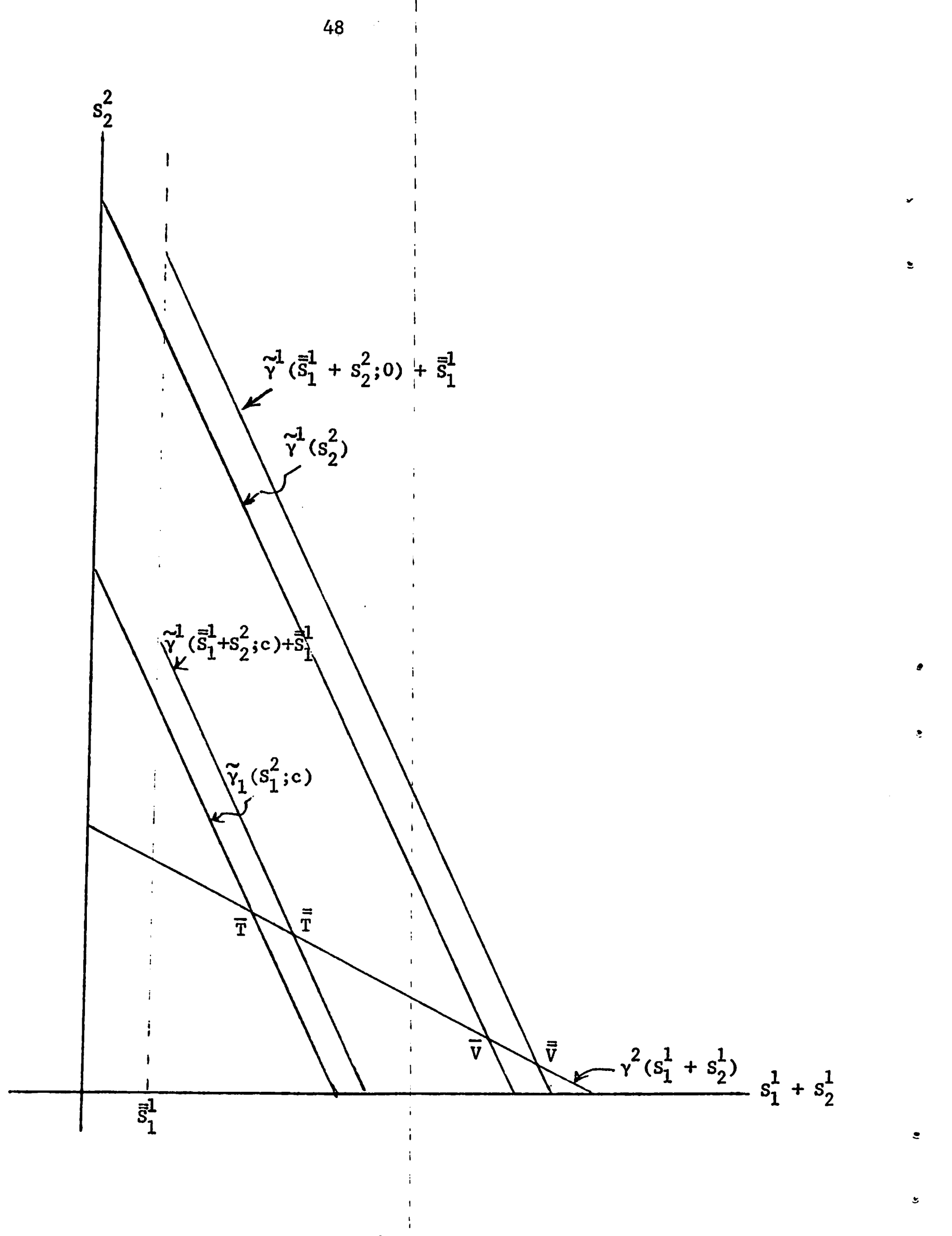

Figure 4 


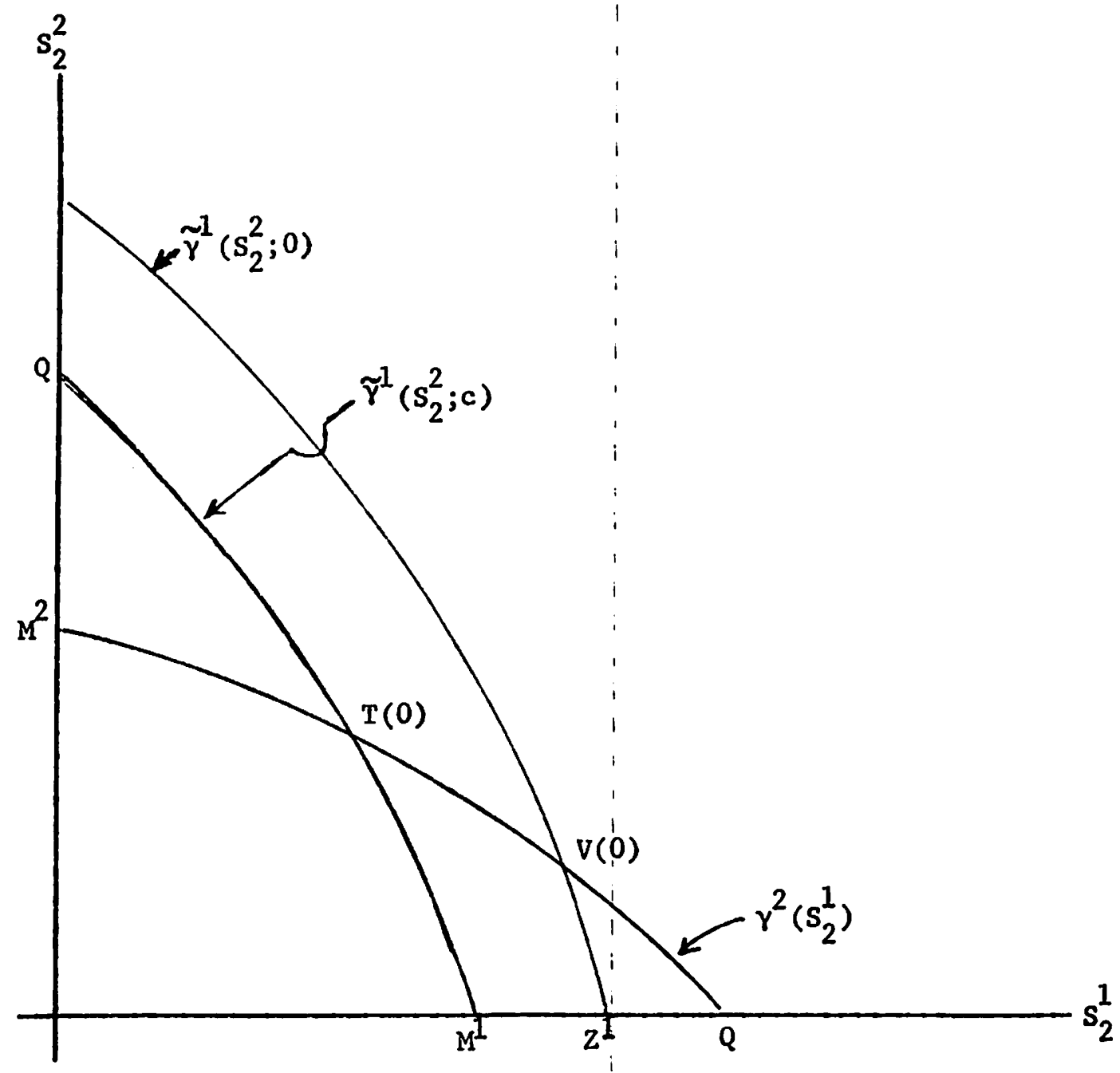

Figure 5 
50

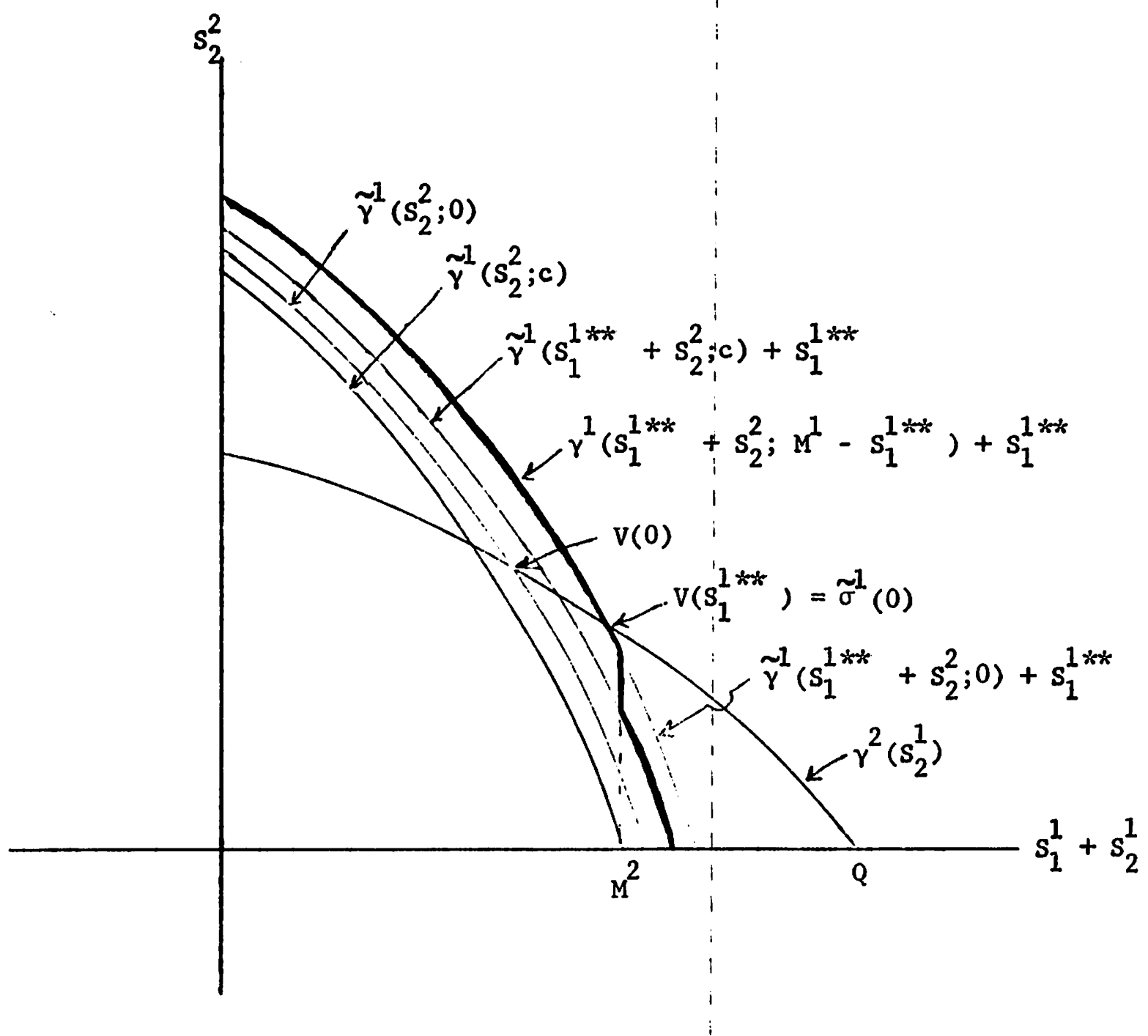

Figure 6 


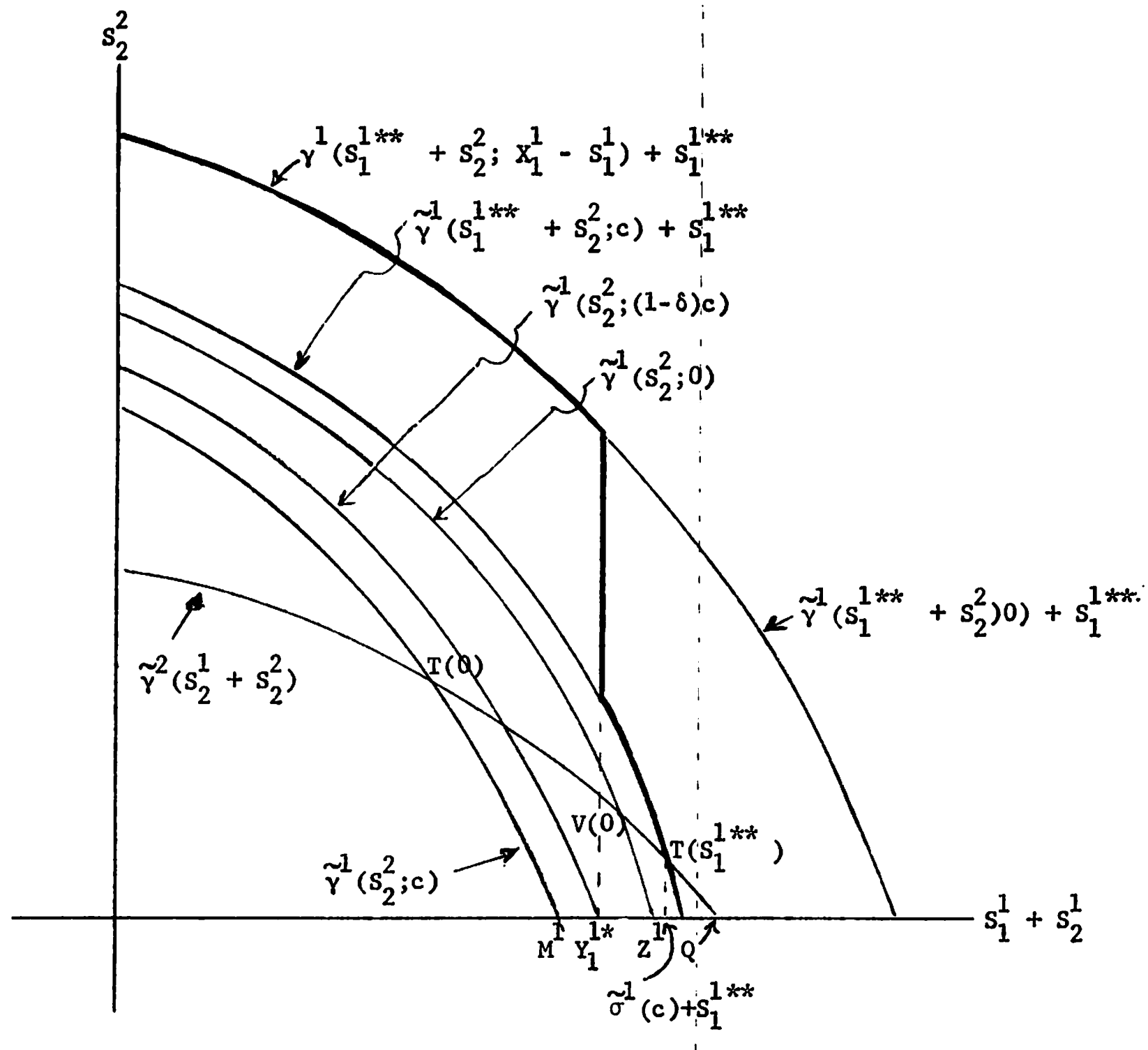

\section{Figure 7}




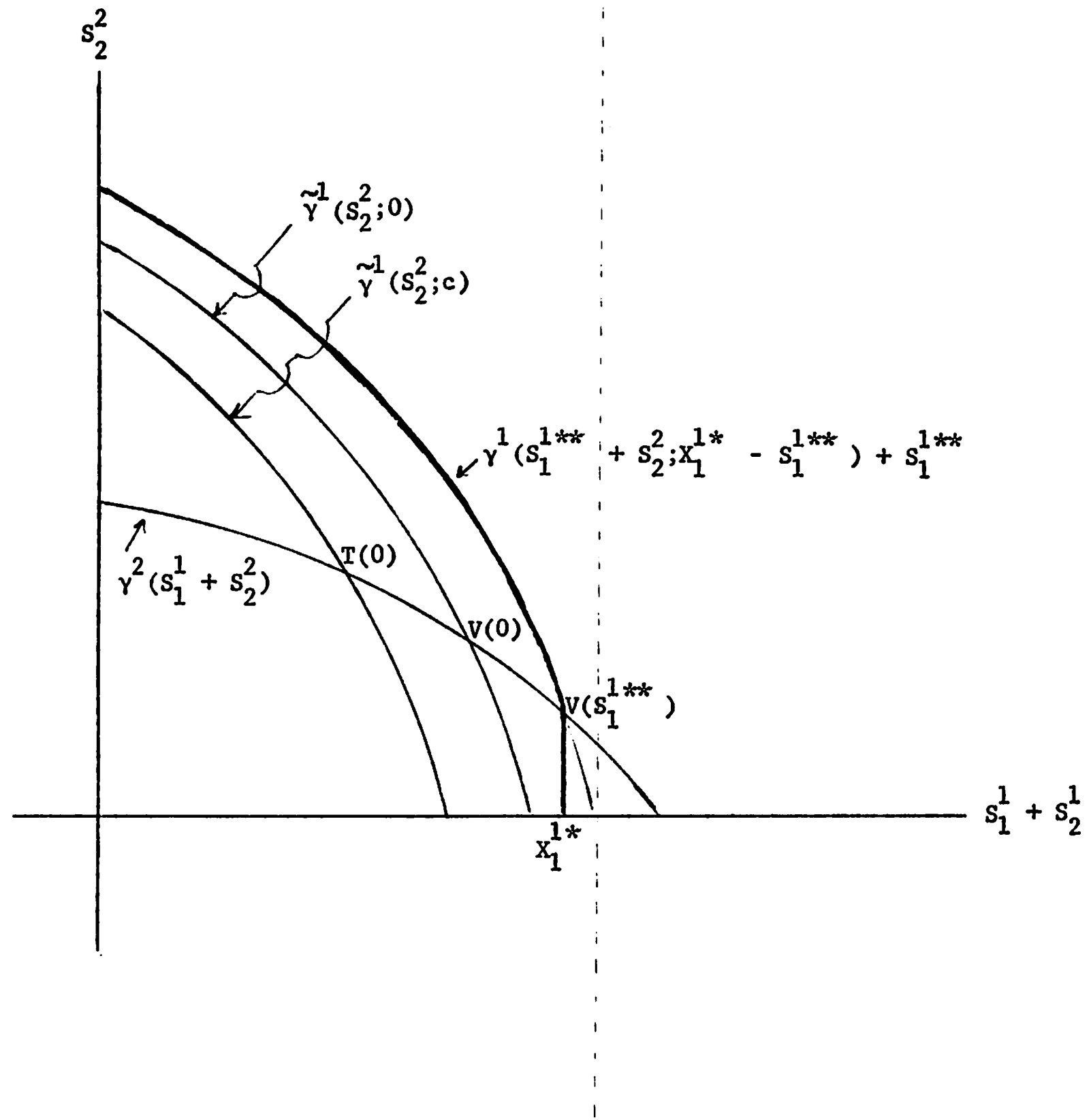

Figure 8 